\author{
Contato \\ Av. Brasil, $4036-4^{\circ}$ andar \\ Sala 417 - Manguinhos \\ 21040-361 - Rio de Janeiro - R \\ lolakury@gmail.com
}

\section{O NATURALISTA VELOSO}

\author{
Lorelai B. Kury"
}

Fundação Oswaldo Cruz

Universidade do Estado do Rio de Janeiro

\title{
Resumo
}

O artigo analisa a atuação de frei Veloso como naturalista e busca demonstrar que tanto sua atividade de botânico quanto o trabalho de editor eram consistentes com as características da história natural do Iluminismo. A celebridade adquirida posteriormente por Veloso foi sendo construída no âmbito da exaltação de "grandes homens" do período colonial e na utilização de suas pesquisas pela botânica. O fato de Veloso e sua equipe terem adotado o sistema lineano permitiu que sua obra fosse reconhecida pelos taxonomistas como válida, mesmo posteriormente, apesar de estar desatualizada na época de sua publicação.

\section{Palavras-chave}

Frei Mariano da Conceição Veloso - história natural - Florae Fluminensis.

* Agradeço as sugestões de Joël Delisle. Patrícia Madeira e Alexander Reis participaram da transcrição de manuscritos. Agradeço a Danielle Sanchez pela reprodução e envio de alguns documentos de Lisboa. A pesquisa contou com apoio do CNPq.

${ }^{* *}$ Doutora em História pela École des Hautes Études en Sciences Sociales. Pesquisadora do Conselho Nacional de Desenvolvimento Científico e Tecnológico - CNPq. Professora do Programa de Pós Graduação em História das Ciências e da Saúde da Casa de Oswaldo Cruz e do Departamento de História do Instituto de Filosofia e Ciências Humanas. 


\title{
VELOSO,
}

\section{THE NATURALIST}

\author{
Contact \\ Av. Brasil, $4036-4^{\circ}$ andar \\ Sala 417 - Manguinhos \\ 21040-361 - Rio de Janeiro - R \\ lolakury@gmail.com \\ Lorelai B. Kury \\ Fundação Oswaldo Cruz \\ Universidade do Estado do Rio de Janeiro
}

\begin{abstract}
This paper analyses Veloso's activities as a naturalist and argues that his botanical work as well as his editor's efforts are consistent with Enlightened natural history. His later celebrity was built by the trend of ennobling "great men" of the colonial rule and by the actual use of his botanical research. The fact that Veloso and his group adopted the Linnean system allowed his work to be recognized by taxonomists, despite being outdated at the time it was published.
\end{abstract}

\section{Keywords}

Friar Mariano da Conceição Veloso - natural history - Florae Fluminensis. 
A avaliação historiográfica dos considerados "grandes homens" é variável e sujeita a revisões, como todas as outras matérias. Assim acontece com frei Mariano da Conceição Veloso. Desde o século XIX, duas de suas obras são postas em destaque: Fazendeiro do Brasil e Florae Fluminensis. ${ }^{1}$ É comum que os historiadores das ciências tradicionais valorizem mais a "flora" do que as atividades de editor, o que corresponde ao tipo de especialização da segunda metade do século XIX e não a uma avaliação corrente no período de atuação do religioso. Nas últimas décadas, com o incremento dos estudos sobre história da imprensa e da leitura, a atuação de Veloso à frente da Tipografia do Arco do Cego ganhou maior destaque na historiografia. ${ }^{2}$ As reflexões que se seguem buscam compreender o trabalho de Veloso em história natural a partir de questões sobre a prática científica na Ilustração lusa e brasileira, sua materialidade e seus pressupostos. Buscarei afastar-me das avaliações da obra do naturalista efetuadas no século XIX, quando se construíram as biografias de "brasileiros ilustres" do período colonial, mas também me distancio de interpretações posteriores que discutem se a flora de Veloso "já" estaria "ultrapassada", por "ainda" classificar de acordo com o sistema lineano, ou se ele teria sido realmente um "bom" botânico. ${ }^{3}$

A vida de Veloso costuma ser separada em pelo menos duas grandes partes: uma primeira estada no Brasil, entre Minas, São Paulo e Rio de Janeiro, e a carreira em Lisboa, junto a coleções e como editor. Na primeira etapa, seus vínculos de proteção seriam com d. Luís de Vasconcelos - vice-rei do Brasil. A segunda etapa estaria associada às atividades do ministro d. Rodrigo de Sousa Coutinho. Do lado ocidental do Atlântico, Veloso teria produzido sua monumental obra botânica; do lado oriental, passara a cuidar de instituições e, sobretudo, passara a editor. Estranhamente, deixou seus próprios escritos botânicos em estado manuscrito. Sem entrar no debate a respeito do fato da Florae Fluminensis não ter sido publicada durante a vida do autor, gostaria de seguir outro caminho. Pretendo estabelecer pontos que unem

\footnotetext{
1 No título da obra de Veloso, tanto nos manuscritos quanto nas publicações, aparece Florae Fluminensis. O "florae" diz respeito ao restante do título, como consta da bibliografia. Quando em itálico, mantive o título.

2 A principal referência é CAMPOS, Fernanda de et al. (org.). A casa literária do Arco do Cego (17991801) - Bicentenário: "sem livros não há instrução". Lisboa: Biblioteca Nacional/ Imprensa Nacional/ Casa da Moeda, 1999.

3 Ver, por exemplo, a "avaliação" da obra de Veloso, interessante como comparação entre os estudos botânicos da segunda metade do século XIX e os do final do século XVIII: GAMA, José de Saldanha da. Biographia e apreciação dos trabalhos do botanico brasileiro frei José Marianno Conceição Velloso. Rio de Janeiro: Typ. de Pinheiro \& C., 1869.
} 
suas atividades no Velho e no Novo Mundo, pois acredito que a atuação de Veloso no Arco do Cego não o afastou da botânica. Acredito também que uma leitura crítica de seus primeiros biógrafos e das primeiras referências a sua obra pode auxiliar na elaboração de um perfil do naturalista, mais conforme às preocupações dos historiadores das ciências atuais.

\section{Enciclopedismo e utilidade}

O tipo de texto que frei Veloso publicou em Portugal corresponde ao universo de interesses científicos da Europa e das Américas na mesma época. Tratava-se de fazer circular em Portugal a literatura científica corrente internacionalmente. A Encyclopédie francesa, milhares de livros e centenas de publicações periódicas em toda a Europa da Ilustração estampavam verbetes, instruções, memórias e tratados relativos às ciências e às artes, principalmente a agricultura. Muitos periódicos adotaram o modelo enciclopedista, buscando instruir o leitor nas diversas áreas do conhecimento, das letras à agricultura, da política à química. As traduções, tão características do catálogo do Arco do Cego, também estiveram presentes em outros empreendimentos científicos e filosóficos, como é o caso, por exemplo, da Académie des Sciences, Arts et Belles-Lettres de Dijon, que teve atuação importante para a formação de uma "República das Ciências" a partir da segunda metade do século XVIII. ${ }^{4}$ Nessa época, as ciências consideradas úteis ganham maior espaço em uma imprensa que não era especializada.

Em Portugal, acontecia um movimento editorial semelhante, em escala bem menor do que na França e na Inglaterra. O Jornal Enciclopédico, cujo primeiro número saiu em 1779 em Lisboa, segundo Fátima Nunes, foi a matriz do periodismo enciclopédico português. ${ }^{5}$ Em sua primeira configuração, as rubricas eram as seguintes: filosofia, medicina, história natural, literatura, economia civil e rústica, anedotas $\mathcal{E}$ miscelânea, relações políticas dos diferentes estados do mundo, produções literárias de todas as nações. ${ }^{6}$ Outros periódicos ofereciam conteúdos mais específicos e direcionados para outros

\footnotetext{
${ }^{4}$ Ver BRET, Patrice. "Ils ne forment tous q'une même république": Académiciens, amateurs et savants étrangers dans la correspondance des chimistes à la fin du 18e. siècle. Dix-Huitième Siècle, 40, 2008, p. 263-279.

5 NUNES, Maria de Fátima. Imprensa periódica científica (1772-1852). Lisboa: Estar, 2001, p. 56.

${ }^{6}$ REIS, Fernando Egídio. Felicidade, utilidade e instrução. A divulgação científica no Jornal Enciclopédico dedicado à rainha; 1779; 1788-1793; 1806. Porto: Porto Editora, 2005, p. 18.
} 
tipos de público, como as Memórias da Academia das Ciências de Lisboa e jornais dedicados às matemáticas ou à medicina e cirurgia.

Veloso, em 1796, esteve à frente do Paládio português, ou Clarim de Palas, que anuncia periodicamente os novos descobrimentos na agricultura, artes, manufaturas, comércio etc., cuja linha editorial se aproximava do que iria fazer poucos anos depois à frente da Tipografia do Arco do Cego. O Paládio publicou, por exemplo, uma memória sobre os telégrafos, uma tradução de artigo dos Annales de Chimie sobre instrumentos feitos com goma elástica de borracha do Brasil, notícias sobre couro impenetrável à água, conservação de manteiga sem ranço, além de descrições de privilégios industriais publicados principalmente na Inglaterra, como: “Do novo método de separar o ferro das pedras que lhe servem de matriz, e de passar para o estado de barra, ou ferro fundido, descoberto por Guilherme Fullarton, (...) conforme a condição do Alvará de Privilégio. Datado aos 19 de junho de 1792". Este tipo de tema ganhava cada vez mais espaço na imprensa, tendo em vista as transformações que ocorriam no âmbito dos privilégios industriais, patentes e da propriedade intelectual. ${ }^{7}$

A publicação de obras botânicas especializadas em Portugal era relativamente pequena. Vandelli, Brotero, João de Loureiro, Correia da Serra, entre outros, tiveram escritos impressos. Porém, a história natural era um campo amplo, com pouca especialização interna e que incluía as ciências e suas aplicações. Ou seja, um mesmo autor poderia descrever morfologicamente alguma planta e discorrer também sobre seu cultivo. A literatura científica do Iluminismo tendia, justamente, a valorizar a aplicação dos conhecimentos. Os manuais e as instruções práticas, com ou sem imagens, eram gêneros científicos comuns na época. Algumas dessas obras eram empregadas no ensino técnico e superior, civil ou militar. Outras publicações, porém, circulavam de maneira independente do ensino formal e institucional. Este tipo de texto tinha a intenção de mostrar como controlar técnicas e como utilizar máquinas e instrumentos.

Parte importante do catálogo do Arco do Cego era dedicada aos métodos de aprendizagem e às instruções técnicas. Essa editora publicou, entre outros, memórias sobre os adubos, um método para aprender pintura em três horas, uma instrução sobre a cultura da batata e outra para retirar água de navios sem trabalho humano. Veloso teve particular empenho em povo-

\footnotetext{
7 Ver BIAGIOLI, Mario. From print to patents: living on instruments in early modern Europe. History of Science, XLIV, 2006, p. 139-186.
} 
ar os impressos de imagens, tendo formado, inclusive, oficinas dedicadas ao aprendizado de técnicas de desenho e gravura. ${ }^{8}$

A obra de botânica "não aplicada" realizada por Veloso e seu grupo, a Florae Fluminensis, não pode ser considerada uma produção apartada do universo de publicações úteis do mercado editorial das Luzes, nem do âmbito das atividades economicamente atraentes. O franciscano procedeu à descrição, classificação e remessa de plantas do Rio de Janeiro a pedido do vice-rei d. Luís de Vasconcelos e Souza e recebeu recursos financeiros para a realização de excursões. Veloso, além de plantas, enviou sementes, insetos, conchas, e outros objetos de história natural.9 Certamente, estes objetos portavam valores múltiplos, inclusive o do agradar pela beleza e pela curiosidade. Em Lisboa, Veloso ressaltaria esse aspecto de seu trabalho, como foi o caso de um belo artefato que produziu, com uma técnica que estampava borboletas com uma "fécula colorante".10 É importante, no entanto, situar a história natural na convergência entre uma cultura aristocrática do saber desinteressado, em declínio, e uma cultura que legitimava a ciência como um modo de proporcionar maior bem-estar material para a "humanidade", típica das Luzes.

Inventariar a flora da capitania tinha um objetivo utilitário evidente, já que identificar exatamente cada uma das espécies vegetais locais seria o primeiro passo para a exploração eficaz de produtos naturais, nos moldes da cultura administrativa e científica que os governantes "ilustrados" pretendiam estabelecer na época. O método de descrição, classificação e nomenclatura usado por Lineu foi adotado por muitos botânicos no mundo todo como maneira de uniformizar os procedimentos e universalizar a linguagem científica. Na botânica, estavam presentes também elementos filosóficos importantes, relacionados à compreensão de Deus a partir de suas obras, ou da natureza a partir do estudo de seus reinos. A história natural era capaz de unir reflexões sobre a lógica do mundo e, ao mesmo tempo, ser a ciência que

\footnotetext{
8 FARIA, Miguel. A imagem útil. Lisboa: Universidade Autônoma de Lisboa, 2002 e CAMPOS, Fernanda de et al. (org.). A casa literária do Arco do Cego (1799-1801) - Bicentenário: "sem livros não há instrução". Lisboa: Biblioteca Nacional/ Imprensa Nacional/Casa da Moeda, 1999.

9 Ver SOUZA, Luís de Vasconcelos e. Carta a Martinho de Melo e Castro. Rio de Janeiro, 17 de junho de 1783. In: Livros de registro das cartas régias e de ofício remetidas da Corte e do secretário de Estado da repartição da Marinha e Domínios Ultramarinos, dirigidas a Luís de Vasconcelos e Souza, vice-rei do Brasil. Biblioteca Nacional do Rio de Janeiro, ms. 04, 04, 005.

${ }^{10}$ Ver PEREIRA, Magnus R. de Mello. D. Rodrigo e frei Mariano: a política portuguesa de produção de salitre na virada do século XVIII para o XIX. Topoi, vol. 15, n. 29, 2014, p. 498-526 e VELOSO, José Mariano da Conceição. Ofício ao (secr. de Estado...) d. Rodrigo de Souza Coutinho. Lisboa, 1795. Arquivo Histórico Ultramarino, ms.: AHU, Reino, cx. 30, pasta 7.
} 
se encarrega da efetiva utilização das plantas, dos animais e dos minerais. A Ilustração foi em grande medida justificada por atitudes providencialistas, pias ou laicas, como a historiografia já o tem demonstrado. ${ }^{11} \mathrm{O}$ próprio Lineu é exemplo dessa aliança da prática com a especulação, o que, em parte, explica a força de seu nome, mesmo depois de sua morte. ${ }^{12}$ A separação idealizada entre a história natural teórica e prática nos moldes contemporâneos começa a ser construída a partir das últimas décadas do século XVIII e se configura de maneira relativamente estável durante o século XIX.13 A ciência considerada mais teórica e filosófica passava, então, a se legitimar sem a conexão imediata com sua aplicação. Este não era, no entanto, o mundo de Veloso.

\section{A leitura e as artes}

A confecção da Florae Fluminensis e a atividade editorial em Lisboa se conjugavam, desse modo, no campo da história natural. Outra característica, porém, une as duas fases da vida de Veloso: a cultura impressa do Iluminismo e a crença na estreita relação entre texto e prática científica. Nas publicações do Arco do Cego, esta ligação é clara: a palavra impressa teria o poder de induzir às práticas e de ensiná-las. ${ }^{14}$ As instruções e descrições de técnicas agrícolas são um bom exemplo disso. D. Rodrigo de Sousa Coutinho e o próprio Veloso ambicionavam espalhar essas publicações por todo Brasil, como meio de promover a racionalização e a transformação das práticas tradicionais. Toda a literatura dedicada à agricultura e à economia rural era povoada de referências aos hábitos estabelecidos e às dificuldades de os abandonar. A palavra que mais se utilizava para designar a tradição era "rotina", acompanhada muitas vezes do adjetivo "cega". Apesar dessa constatação, a traduções

\footnotetext{
${ }^{11}$ Ver, entre outros, CALAFATE, Pedro. A ideia de natureza no século XVIII em Portugal. Lisboa: Imprensa Nacional/Casa da Moeda, 1994 e KURY, Lorelai. Histoire naturelle et voyages scientifiques (1780-1830). Paris: L'Harmattan, 2001.

${ }^{12}$ LINNÉ, Carl. L'équilibre de la nature. Textos anotados por Camille Limoges. Paris: J. Vrin, 1972.

13 Parte da historiografia contemporânea das ciências tem buscado demonstrar que o mundo da ciência teórica nunca foi desvinculado do mundo da técnica. Ver, entre outros, SHAPIN, Steven. Never pure. Historical studies of science as if it was produced by people with bodies, situated in time, space, culture and society, and struggling for credibility and authority. Baltimore: The Johns Hopkins University Press, 2010.

${ }^{14}$ A historiografia tem tratado com frequência o problema das relações entre leitura, conhecimento e prática, ciência e técnica. As interpretações são variadas e, por vezes, polêmicas. Ver, por exemplo, o dossiê dedicado à questão do "conhecimento útil" na obra de Joel Mokyr em History of Science, v. XLV, 2007, e também o dossiê da revista Isis, 103:3, sobre "ciências aplicadas", de 2012.
} 
e artigos originais publicados em Lisboa eram creditados poderem alterar de algum modo a realidade.

De fato, apesar da grande maioria dos plantadores ignorar as memórias do Arco do Cego e os volumes de Fazendeiro do Brasil, a circulação de textos, quando conjugada com algum outro tipo de incentivo, poderia surtir algum efeito prático. Uma análise recente sobre o fabrico de anil demonstra que a produção de índigo no Rio de Janeiro chegou a ser exportada em quantidades significativas para o mercado europeu, entre a década de 1770 e 1807. Além do incentivo do governo - que garantia a compra da produção - e da conjuntura internacional favorável, 800 cópias de uma instrução sobre o plantio da anileira e o preparo do corante, datada de 1785, foram distribuídas no Rio de Janeiro e em outras capitanias. ${ }^{15} \mathrm{Um}$ dos manuscritos que se encontra na Biblioteca Nacional contém 10 páginas de texto e uma imagem intitulada "Demonstração sobre o modo de fabricar o anil". ${ }^{16}$ Há também em separado - um conjunto de imagens vinculado ao texto que provavelmente circulava ao mesmo tempo. A instrução foi copiada apenas de forma manuscrita para evitar, segundo Melo e Castro, "por ora fazer maior ruído com esta nossa descoberta do Anil, que não há de ser vista com indiferença pelas outras nações que fazem este comércio". ${ }^{17}$

Em Fazendeiro do Brasil, no volume sobre "tinturaria", o prefácio de Veloso dá vários indícios de como podia acontecer a circulação e a utilização dos textos manuscritos e impressos para a fabricação de algum produto, nesse caso o anil:

Desta sorte, se por um lado favorecidos, por outro abandonados a si mesmos, os fabricantes, homens faltos de toda a instrução, como pela maior parte são os cultivadores, entregues a certas receitas ou mal copiadas, ou mal vertidas, firmados em experiências próprias sem princípios, longe de terem feito progresso algum vantajoso, e apesar de terem sido sustentados, e aguilhoados pelas bondades Régias, se têm recuado, e atrasado lastimosamente neste fabrico. Ora os fenômenos, que apresenta a manipulação

${ }^{15}$ PESAVENTO, Fábio. Novas perspectivas sobre o comércio de anil no Rio de Janeiro colonial: 1749-1820. Revista de História Econômica e de Economia Regional Aplicada, v. 1, n. 1, jan-jul de 2006, p. $1-19$, cf. p. 4 .

16 ABREU, Jeronimo Vieira de. Brevíssima instrucção para uso dos fabricantes de anil nas colonias de sua majestade fidelíssima, 1785. Biblioteca Nacional do Rio de Janeiro, ms., 05, $01,05$.

${ }^{17}$ CASTRO, Martinho de Melo e. Ofício a Luis de Vasconcelos e Souza. Lisboa, 6 de março de 1786. In: Livros de registro das cartas régias e de ofício remetidas da Corte e do secretário de Estado da repartição da Marinha e Domínios Ultramarinos, dirigidas a Luís de Vasconcelos e Souza, vice-rei do Brasil. Biblioteca Nacional do Rio de Janeiro, ms. 04, 04, 008. 
desta fécula, são às vezes tão extraordinários, como expõem estas Memórias, que fazem pasmar aos seus mais atinados, e antigos práticos, e por isso eles são dignos de escusa. ${ }^{18}$

Apenas o incentivo não garantiria por si só um produto de qualidade. Seria necessária instrução, pela forma da escrita e de experiência fundada em princípios claros, que pudesse levar a algum progresso. As memórias que publicava, sem as desvantagens dos manuscritos mal copiados, pretenderiam suprir uma prática bem fundamentada.

As memórias relacionadas à atuação de Veloso circularam de algum modo entre os plantadores e "inventores", embora de forma limitada, tendo em vista o analfabetismo e a falta de hábito em utilizar algum texto como aliado para a produção.Onaturalista Manuel Arruda da Câmara,em carta aoreligioso,comentou:

Estimo muito que me tenha recomendado amizade do Sr. Nabuco; ele ainda cá não chegou, e mais me impacienta a sua tardança pelo desejo que tenho de ver as suas obras, porque de tantas que julgo de V. Revma. ter dado à luz, não vi nenhuma senão o Fazendeiro do Brasil, que ontem me emprestou um Sr. de Engenho e de que ainda não tive tempo senão de ler o Prefácio. ${ }^{19}$

Câmara certamente não era um plantador típico. Estudara em Coimbra e se formara em medicina em Montpellier. De volta ao Brasil, foi encarregado por d. Rodrigo de pesquisar as nitreiras naturais das capitanias do nordeste e as plantas que poderiam servir para a fabricação de cordas. Além disso, aplicou seus conhecimentos para implementar inovações em sua propriedade, na qual plantava algodoeiros, utilizando trabalho escravo, de acordo com o sistema vigente à época. Câmara, entre outras coisas, introduziu em sua produção uma prensa para ensacar algodão. Esse médico, naturalista e plantador, fazia uso intensivo da leitura associada ao trabalho científico e à transformação técnica. Ele mesmo produziu textos informativos e didáticos sobre novos procedimentos agrícolas e sobre botânica, muitos dos quais publicados por Veloso. Seus escritos foram frequentemente acompanhados por imagens, ferramenta importante para as publicações do período. ${ }^{20}$

\footnotetext{
${ }^{18}$ VELLOSO, José Mariano da Conceição. Fazendeiro do Brasil. Tomo II, parte I, Tinturaria. Lisboa: Impressão Régia, 1806, sem paginação.

${ }^{19}$ CÂMARA, Manuel Arruda da. Carta a frei José da Conceição Veloso. Recife, 2 de junho de 1799, p. 5. Museu Paulista, ms. I.1 I-2-2-275, p. 5.

${ }^{20}$ Ver KURY, Lorelai. Manuel Arruda da Câmara: a República das Letras nos sertões. In: Idem (org.). Sertões adentro: viagens nas caatingas, séculos XVI a XIX. Rio de Janeiro: Andrea Jakobsson Estúdio, 2012.
} 
O cartógrafo e governador da capitania do Espírito Santo, Antonio Pires da Silva Pontes Leme, em carta a d. Rodrigo de Sousa Coutinho, datada de 1798, deixou alguns indícios sobre a maneira como os textos e as práticas se encontravam:

Vossa Excelência perdoa falar em tão pequenas cousas, mas não se pode seguir mal
de Vossa Excelência o saber; todo o trabalho do Pe. Veloso está pago quando menos
pelo benefício das moendas dos engenhos com o cilindro ou eixo do meio de menor
diâmetro; o Bolcão (...) foi o primeiro a abrir o exemplo com tal sucesso que ouvi ao
Brigadeiro Clarke e a outros que andam bambos os tirantes das moendas e que passam
os feixes de cana em maior cópia e sem pejar o andamento do engenho, e tem sido uma
romagem dos lavradores a irem ver a máquina; agora pedem a forma das taxas [tachos]
com seu petipé, o modo de servir-se das de ferro (...), pedem à sua custa algum prático da
Jamaica, e a tradução dos termos de medidas inglesas, como galons, a de jeiras, ou acres. ${ }^{21}$

Este interessante testemunho demonstra o entrelaçamento entre leitura, tradução, observação de imagens, difusão das práticas e formas de transmissão da experiência. A referência ao recurso a um "prático da Jamaica" pode indicar uma das formas de interação entre textos e aprendizado prático nesse circuito das "artes" e da ciência útil no mundo colonial. ${ }^{22}$

\section{A botânica}

A Florae Fluminensis de Veloso constitui uma outra vertente das ciências das Luzes, também útil, mas não imediatamente aplicada. As descrições das plantas feitas pelo religioso são basicamente morfológicas, com menção ao lugar de coleta e, por vezes, com informações adicionais sobre o nome científico e os nomes locais. Os usos apenas são mencionados de forma geral, sem maiores detalhes, como, por exemplo, “240. Drymys. (...) Caulis arboreus. Folia ob-ovata, glabra. Petala undecim, sub-linearia. Pistilla quinque. Perianthium

${ }^{21}$ LEME, Antonio Pires da Silva Pontes. Carta a d. Rodrigo de Sousa Coutinho. Bahia, 5 de abril de 1798. Manuscrito. Biblioteca Nacional do Rio de Janeiro. Transcrito em SILVA, Andrée Mansuy-Diniz. Portrait d'un homme d'État: d. Rodrigo de Souza Coutinho, comte de Linhares, 1755-1812, vol. II: L'homme d'État, 1796-1812. Paris: Centre Culturel Calouste Gulbenkian, 2006, p. 557.

${ }^{22}$ Ver KURY, Lorelai. A ciência útil em O patriota (Rio de Janeiro, 1813-1814). Revista Brasileira de História das Ciências, v. 4, 2011, p. 31-41 e MARQUESE, Rafael de Bivar. Feitores do corpo, missionários da mente. Senhores, letrados e o controle dos escravos nas Américas, 1660-1860. São Paulo: Companhia das Letras, 2004. Ver, para comparação, o caso francês em McCLELLAN III, James E. E REGOURD, François. The colonial machine: French science and overseas expansion in the old regime. Turnhout: Brepols Publishers, 2011. 
diphyllum. Cortex arboris acer. Rusticani ad varios usus medicos adhibent. Vulgó dicitur casca d'Anta. Habitat campis apricis mediterraneis transalpinis. Floret Sept. Oct". ${ }^{23}$

Assim, a grande obra botânica de Veloso é um inventário das espécies vegetais coletadas na capitania do Rio de Janeiro (e trechos de São Paulo). A classificação e a descrição nos moldes lineanos garantia universalidade ao trabalho, ou seja, permitia que fosse compreendido e considerado válido por outros naturalistas de sua época, se o trabalho viesse a ser publicado. Como não há notícias sobre seu herbário, as imagens publicadas a partir de 1831 servem como referência quando associadas ao texto que as deveria acompanhar, publicado em partes em 1825 (circulando efetivamente a partir de 1829) e 1881. ${ }^{24}$

No século XVIII, para se fazer botânica em uma região ainda pouco explorada por naturalistas - como a América portuguesa - era necessário algum tipo de formação e aprendizado. Porém, nada que se compare à incrível especialização e ampliação do conhecimento botânico, que ocorre a partir do fim de Setecentos. Ser especialista em plantas nas primeiras décadas do século XIX passa a exigir outras práticas, não estabilizadas no século anterior. Por exemplo, as grandes viagens científicas do Iluminismo deixaram como saldo uma infinidade de plantas classificadas, provenientes dos quatro cantos do mundo. Os herbários formados nos grandes centros europeus passaram a ser referenciais para os estudos. Além disso, a quantidade de obras publicadas aumentou enormemente. No caso brasileiro, a grande transformação se dá a partir dos resultados das viagens empreendidas no contexto da Restauração de 1815. Alguns naturalistas passaram a elaborar projetos de síntese do material, como é o caso de Carl-Friedrich-Philipp von Martius e a publicação paulatina da Flora Brasiliensis, entre 1840 e 1906.

Outra mudança relevante no âmbito da botânica é a substituição dos critérios de classificação propostos por Lineu pelo sistema de Antoine Laurent de Jussieu, exposto em seu Genera plantarum (1789), que incluía uma gama mais ampla de caracteres distintivos, embora a nomenclatura binomial adotada pelo sueco fosse mantida.

A prática da herborização e os livros foram os mestres de Veloso. Ele provavelmente aprendeu os procedimentos internacionais da botânica do século XVIII a partir da leitura de Lineu e das floras publicadas a que teve acesso em Minas, São Paulo e no Rio. As ordens religiosas mantinham tra-

\footnotetext{
${ }^{23}$ VELLOZO, Mariano da Conceição. Florae Fluminensis seu descriptionum plantarum praefectura fluminensi sponte nascentium... Rio de Janeiro: Machado E C., 1881, p. 226.

${ }^{24}$ Ver Flora Fluminensis. Documentos. Rio de Janeiro: Arquivo Nacional, 1961.
} 
dicionalmente bibliotecas, boticas e possivelmente herbários. Mesmo antes da botânica lineana, outros sistemas de classificação eram adotados, muitas vezes relacionados aos usos das plantas. ${ }^{25}$ Desse modo, Veloso teve acesso a livros de história natural provavelmente no Convento de São Francisco, em São Paulo, e no Convento de Santo Antônio, ${ }^{26}$ no Rio de Janeiro, onde se formou e atuou, inclusive ensinando botânica. O Convento de São Boaventura de Macacu (no atual distrito de Itaboraí, Rio de Janeiro), onde tomou o hábito, talvez também possuísse uma boa biblioteca.

O botânico brasileiro Francisco Freire Alemão (1797-1874) avaliou que Veloso teria tido como "principal guia (...) provavelmente" a obra de Charles Plumier (1646-1704). O padre Plumier, religioso da ordem dos Mínimos, explorou as Antilhas por diversas vezes e deixou obra extensa e consagrada sobre a flora da América. ${ }^{27}$ Ele era próximo de Joseph Pitton de Tournefort (1656-1708), cujo método de classificação e de descrição foi dos mais influentes ao longo de todo o século XVIII. Muitos gêneros de Plumier foram mantidos por Lineu, em sua sistematização do reino vegetal. Além dele, Freire Alemão elenca Guilherme Piso, que seria referência geral para todos que estudassem a flora do Brasil, mas também identifica a leitura da obra de Jean-Baptiste Fusée-Aublet (1720-1778) - que viajou pela Guiana francesa ${ }^{28}$ - e se pergunta sobre as obras de Nikolaus-Joseph Jacquin:29 "teria delas conhecimento o nosso Veloso?"30

Estudos e inventários sobre as plantas da América portuguesa eram raros quando Veloso preparava a Florae Fluminensis. Os trabalhos de naturalistas que exploraram regiões vizinhas se tornavam, assim, essenciais. A obra do padre Plumier, embora fizesse parte do mundo pré-lineano, continuou uma

\footnotetext{
${ }^{25}$ Sobre o uso de plantas pelas ordens religiosas, ver, por exemplo, os estudos: FLECK, Eliane. Sobre licores e xaropes: práticas curativas e experimentalismos jesuíticos nas reduções da província jesuítica do Paraguai (séculos XVII-XVIII). In: KURY, Lorelai \& GESTEIRA, Heloisa (org.). Ensaios de história das ciências no Brasil: das Luzes à nação independente. Rio de Janeiro: EdUerj, 2012 e GESTEIRA, Heloísa. As virtudes das plantas: circulação de ideias e práticas médicas na América, séculos XVI-XVIII. In: ALMEIDA, Marta de E VERGARA, Moema (org.). Ciência, história e historiografia. Rio de Janeiro: Via Lettera, 2008.

${ }^{26}$ RÖWER, frei Basílio. O Convento de Santo Antônio do Rio de Janeiro. Sua história, memórias, tradições. Rio de Janeiro: Jorge Zahar, 2008.

${ }^{27}$ PLUMIER, Charles. Description des plantes de l'Amérique avec leurs figures. Paris: Imprimerie Royale, 1693.

${ }^{28}$ FUSÉE-AUBLET, Jean-Baptiste. Histoire des plantes de la Guiane françoise rangées suivant la méthode sexuelle. Paris: Didot jeune, 1775.

29 ACQUIN, Nikolaus Joseph. Selectarum stirpium Americanarum historia. Viena: Of. Krausiana, 1763.

${ }^{30}$ ALEMÃO, Francisco Freire. Notícias a respeito dos naturalistas Joaquim Veloso de Miranda e José Mariano da Conceição Veloso, colhidas de vários informantes, 1849. Biblioteca Nacional do Rio de Janeiro, ms. I - 28, 09, 54.
} 
referência importante ao longo do século XVIII e mesmo do XIX. Os desenhos da obra Descriptions des plantes de l'Amérique, de 1693, podem, efetivamente, ter servido de modelo aos desenhistas de Veloso, como se pode verificar pelo tipo de traço (ver imagem A). A diferença fundamental é que na Florae Fluminensis há a representação em destaque principalmente das partes reprodutivas da flor, de modo a demonstrar seu pertencimento às classes estabelecidas no sistema de Lineu (ver imagem B). As representações de Aublet são, por sua vez, bem mais modernas que as da obra de Plumier e de Veloso, tanto no que concerne à representação geral do vegetal em termos de profundidade e sombra quanto, sobretudo, no que diz respeito à adequação ao sistema lineano, de forma mais detalhada que as imagens do Florae Fluminensis (ver imagem C).

A leitura e a cópia eram elementos importantes para o aprendizado da história natural. Para que se realizassem as descrições das plantas nos moldes de Lineu era necessário dominar o repertório de palavras e imagens contido em suas principais obras e seu significado - sua sintaxe e sua semântica, na expressão de uma analista recente. ${ }^{31}$ Diversos naturalistas em várias partes do mundo publicaram obras que sintetizavam, em quadros e tabelas, as classes e ordens de Lineu, com imagens mostrando estames e pistilos, baseadas em desenhos executados por Georg Ehret em 1736 (imagem D) e publicados em 1737 no Genera plantarum, do sueco. ${ }^{32}$ Além disso, publicavam-se também as imagens de tipos de folhas, raízes, troncos, flores etc., com seus nomes descritivos em latim, extraídas, em geral, do Philosophia botanica (1751), ${ }^{33}$ também de Lineu. O livro Dicionário dos termos técnicos de história natural, extraídos da obra de Lineu... (1788), de Domenico Vandelli, ${ }^{34}$ organiza o vocabulário e as representações necessárias para a prática da história natural de acordo com o modelo lineano (imagem E).

O “Mappa botanico para uzo do ilmo. e exmo. sr. Luis de Vasconcellos e Soiza", 35 manuscrito que se encontra na Biblioteca Nacional do Rio de Janeiro, demonstra como se deu parte da preparação para as excursões do franciscano pela capitania. Provavelmente sob a orientação de Veloso, o "mapa" foi

\footnotetext{
${ }^{31}$ Ver NICKELSEN, Kärin. Draughtsmen, botanists and nature: the construction of eighteenth-century botanical Illustration. Dordrecht: Springer, 2006.

${ }^{32}$ LINNAEUS, Carolus. Genera plantarum. Leiden: C. Wishoff, 1737.

33 LINNAEUS, Carolus. Philosophia botanica. Estocolmo: G. Kisseweter, 1751.

${ }^{34}$ VANDELLI, Domingos. Dicionário do termos técnicos de história natural. Coimbra: Real Oficina da Universidade, 1788.

35 [RANGEL, José Correa]. Mappa botanico para uzo do ilmo. e exmo. sr. Luis de Vasconcellos e Soiza, s. l., s. d. Biblioteca Nacional do Rio de Janeiro, ms. 49, 03, 07, n. 4.
} 
desenhado por José Corrêa Rangel, “ajudante de Infantaria com exercício de Engenheiro", designado pelo vice-rei para acompanhar o religioso. ${ }^{36}$ Extraídas da obra de Lineu ou de fontes secundárias, as pranchas organizam as 24 classes de Lineu, com detalhes de sua representação pictórica, semelhantes aos de Ehret (imagens F e G). Essa era a base para a confecção dos desenhos de história natural. Outro documento da Biblioteca Nacional, pertencente à Coleção Castelo Melhor, pode ter relação com as expedições de Veloso. Seu título é "Resumo do sistema sexual botânico" e consiste em um texto didático e resumido sobre o sistema de Lineu, que explica como proceder para identificar espécimes, chegando até o gênero ao qual pertenceriam. Esse manuscrito pode ser uma cópia de alguma das inúmeras edições do final do século XVIII, baseadas nos textos lineanos. Anexadas ao texto, doze figuras de partes de plantas, baseadas também nas gravuras que ilustram os textos de Lineu. Os desenhos são assinados por "Correa", possivelmente o mesmo José Correa Rangel. ${ }^{37}$

Veloso teve contato com a coleta de vegetais nas missões onde esteve, como as de São Miguel e de Nossa Senhora dos Prazeres (Itapecerica da Serra), ambas na capitania de São Paulo, além de no próprio Rio de Janeiro. ${ }^{38}$ Quando chegou à capital, vindo de São Paulo, seus talentos para a história natural já tinham sido notados por d. Luís de Vasconcelos:

Quanto à remessa das Plantas, até agora me tinha servido de diversas pessoas (...); porém tendo chegado de São Paulo a esta Cidade um Religioso Franciscano desta Província, chamado Frei José Mariano da Conceição Veloso, e achando nele conhecimento, boa vontade, e talento para semelhante trabalho, e aplicação, me tenho aproveitado do seu préstimo, que na realidade me promete grandes progressos, porque já me tem apresentado algumas descrições principiadas, e figuras das Plantas, que tem notado, cuja coleção espero que possa ser muito agradável a S. Magestade. ${ }^{39}$

\footnotetext{
${ }^{36}$ SOUZA, Luís de Vasconcelos e. Carta a Martinho de Melo e Castro. Rio de Janeiro, 17 de junho de 1783. In: Livros de registro das cartas régias e de ofício remetidas da Corte e do secretário de Estado da repartição da Marinha e Domínios Ultramarinos, dirigidas a Luís de Vasconcelos e Souza, vice-rei do Brasil. Biblioteca Nacional do Rio de Janeiro, ms. 04, 04, 005. Sobre Rangel, ver PATACA, Ermelinda Moutinho. Terra, água e ar nas viagens científicas portuguesas (1755-1808). Tese de doutorado, Campinas, Instituto de Geociências, 2006, p. 27, 180, 182, 184 e 280.

${ }^{37}$ Resumo do systema sexual botanico. Biblioteca Nacional do Rio de Janeiro, ms. I - 13, $02,13$.

${ }^{38}$ Ver PATACA, E., op. cit., p. 279.

${ }^{39}$ SOUZA, Luís de Vasconcelos e. Carta a Martinho de Melo e Castro, op. cit.
} 
Reconhecer plantas, saber onde e como coletá-las era algo que talvez Veloso possa ter aprimorado no contato com os indígenas, que tinham conhecimento profundo das matas, embora, é claro, os padrões e objetivos desses últimos fossem inteiramente distintos dos da botânica iluminista. Mesmo as descrições da Florae Fluminensis e, de forma geral, os escritos de botânica, continham indicações da presença de informantes locais. Sabe-se que durante suas expedições no entorno do rio Paraíba do Sul tinha se deparado inclusive com índios hostis, os Ararizes, que tentara converter. ${ }^{40}$ Sem guias e ajudantes que colhessem plantas de difícil acesso e conhecessem lugares onde pudessem encontrar diferentes espécies e variedades, muito menos teria sido feito pelos viajantes e coletores. As informações sobre o processo de interação dos naturalistas com os habitantes, guias, ajudantes e demais auxiliares é comumente sumária, mas seria um erro grave não reconhecer que o trabalho realizado nas expedições era fundamentalmente coletivo. ${ }^{41}$ No caso da Florae Fluminensis, o próprio manuscrito foi elaborado de forma coletiva, já que Veloso era auxiliado, entre outros, por frei Anastácio de Santa Inez, que escrevia as descrições dos vegetais em latim, e por frei Francisco Solano, desenhista. ${ }^{42}$ Em seus "giros" pela capitania, também foi auxiliado, por exemplo, pelo já mencionado "José Corrêa Rangel, não só por ser preciso um Oficial, para fazer pôr prontos todos os auxílios, que são necessários, para a diligência, de que se trata, com mais Respeito às Ordens, que tenho dado para este fim, mas porque tem grande habilidade para debuxar as plantas", como indicou d. Luís de Vasconcelos. ${ }^{43}$

Finalmente, pode-se conceber que Veloso mantivesse um horto, prática comum entre os religiosos, médicos e botânicos. Francisco Freire Alemão indicou que o informante coronel Conrado [Niemeyer] teria dito que o naturalista possuía um jardim no Convento de Santo Antônio, mas já na época

\footnotetext{
${ }^{40}$ VELOSO, José Mariano da Conceição. Ofício ao (secr. de Estado...) d. Rodrigo de Souza Coutinho. Lisboa, 1795. Arquivo Histórico Ultramarino, ms.: AHU, Reino, cx. 30, pasta 7.

${ }^{41}$ Ver discussão interessante sobre mudança no reconhecimento do papel dos nativos americanos para o conhecimento colonial em SCOTT-PARISH, Susan. American curiosity. Cultures of natural history in the colonial British Atlantic world. Williamsburg: Omohundro Institute of Early American History and Culture, 2006.

${ }^{42}$ VELOSO, Mariano da Conceição. Florae Fluminensis seu discriptionum plantaru praefectura fluminensi sponte nascentium liber primus ad systema sexuale, $2 \mathrm{v}$. [1790]. Biblioteca Nacional do Rio de Janeiro, ms. 02, 04, 005-006 e VELOSO, Mariano da Conceição. Florae Fluminensis: Icones fundamentales, 11 v., [1790]. Biblioteca Nacional do Rio de Janeiro, ms. I - 17, 01, 001 - I - 17, 06, 001.

${ }^{43}$ SOUZA, Luís de Vasconcelos e. Carta a Martinho de Melo e Castro, op. cit. Sobre a equipe que acompanhou Veloso, ver PATACA, E., op. cit., p. 280.
} 
de seu retorno de Portugal. ${ }^{44}$ Sabe-se também que os franciscanos possuíam um jardim (cerca) aos pés do morro de Santo Antônio.

Desse modo, a obra botânica de Veloso estava alicerçada por uma série de práticas e possibilidades, como as tradições franciscanas, o uso de livros, o auxílio de desenhistas, coletores, informantes locais, além da obediência devida e proteção recebida de um vice-rei ilustrado. D. Luís de Vasconcelos provavelmente foi essencial ao próprio direcionamento dos trabalhos do padre para a história natural, como trecho de sua correspondência oficial indica:

Este Religioso é conceituado na sua Província, na qual tem 22 anos de hábito, e 15 de Pregador. Já foi Professor de Retórica em São Paulo com bom crédito, e [tentava?] para Cronista da mesma Província; o que não consenti, porque semelhante ocupação era incompatível com a diligência, de que o tenho encarregado: Lugar aquele de grande consideração entre os Frades, e que tem anexos seus privilégios, que eles muito estimam. ${ }^{45}$

O sistema lineano adotado por Veloso permitia, como foi dito, a homogeneização da linguagem e dos procedimentos de descrição. Esta foi uma ferramenta importante para a organização da história natural na segunda metade do século XVIII e serviu para que a Florae Fluminensis fosse reconhecidamente uma obra de botânica até os dias atuais. Uma comparação interessante pode ser feita com um trabalho manuscrito realizado pelo capitão Domingos Alves Branco Muniz Barreto, escrito na mesma época da obra de Veloso. O militar atuou no sul da Bahia, na administração dos aldeamentos indígenas e também para estabelecer usos mais diligentes das matas. $\mathrm{O}$ manuscrito em questão é uma lista de plantas medicinais, com desenhos aquarelados, com exposição sucinta de suas virtudes e uma pequena descrição textual do aspecto de cada vegetal, enviado à Academia das Ciências de Lisboa, em finais do século XVIII. Muniz Barreto, como ele mesmo escreveu, era "estrangeiro na ciência da história natural". ${ }^{66}$ As imagens que apresentou ilustravam a aparência e o tamanho natural dos galhos e folhas que, segundo ele, seria um modo eficaz de reconhecer facilmente as plantas:

\footnotetext{
${ }^{44}$ ALEMÃO, Francisco Freire. Notícias..., op. cit.

${ }^{45}$ SOUZA, Luís de Vasconcelos e. Carta a Martinho de Melo e Castro, op. cit.

${ }^{46}$ BARRETO, Domingos Alves Branco Muniz. Relação que contém por lembrança a descrição de uma diminuta parte da comarca dos Ilhéus desta capitania da Bahia, por onde viajei, e do que nela observei. Manuscrito. Biblioteca da Academia das Ciências de Lisboa, transcrito em O feliz clima do Brasil. Rio de Janeiro: Dantes, 2008, p. 54.
} 
meu sistema, que é de estampar uma pequena parte da rama de qualquer vegetal ou arbusto de modo que por elas, ainda [que] sem inteligência, se possa procurar nos campos o que se precisar, nem por isso (com mais juízo e vagar do que não tive) se devem também deixar de estampar no todo os mesmos vegetais, demonstrando o seu caule, ou tronco, a sua configuração etc. ${ }^{47}$

Esse documento ficou esquecido durante dois séculos nos arquivos da Academia das Ciências de Lisboa. Porém, mesmo que tivesse sido divulgado, dificilmente teria se integrado aos circuitos da botânica que já eram regidos por convenções relativamente estáveis. Nesse caso, um funcionário qualificado para algumas atividades essenciais não acompanhara a cientificização da história natural. ${ }^{48}$

\section{A posteridade botânica de Veloso}

O nome do religioso consta atualmente como sendo o primeiro a descrever diversas espécies brasileiras e mais se tem feito para dar a ele prioridade em alguns casos. A publicação tardia dos textos fez com que muita coisa descrita por Veloso no manuscrito de 1790 só começasse a ter validade para a taxonomia botânica depois que outros naturalistas já haviam publicado a respeito, perdendo, assim, em diversos casos, a prioridade. ${ }^{49}$ Desse modo, no que concerne à botânica, o material impresso adquiriu um tipo de valor diferente ao que era atribuído ao manuscrito.

O valor da obra de Veloso, no entanto, varia com o tipo de apropriação que se faz dela e com as relações que pode ter com os lugares e as coisas. Acredito, por exemplo, que o episódio da invasão francesa em 1807 e 1808 e a atuação do zoólogo Étienne Geoffroy Saint-Hilaire ajude a esclarecer sobre a importância que os manuscritos da Florae Fluminensis poderiam ter

\footnotetext{
${ }^{47}$ BARRETO, Domingos Alves Branco Muniz. Regras pelas quais se devem estampar as ervas medicinais e fazer recolher as suas ramas e raízes em tempos próprios, não só do modo que apontam os melhores autores, mas segundo as reflexões que tenho feito a este respeito. Manuscrito. Biblioteca da Academia das Ciências de Lisboa. Transcrito em $O$ feliz clima do Brasil. Rio de Janeiro: Dantes, 2008, p. 97-98.

${ }^{48}$ Segundo o próprio Muniz Barreto a pesquisa sobre os usos que os indígenas faziam das plantas medicinais era apenas um pretexto para travar contato com populações refugiadas nas matas.

${ }^{49}$ Ver LIMA, Haroldo C. de. Leguminosas da Florae Fluminensis - J. M. da C. Vellozo - lista atualizada das espécies arbóreas. Acta Botanica Brasilica, v. 9, n. 1, julho de 1995, p. 123-146.
} 
naquela conjuntura específica, quando as coleções do Brasil se encontravam principalmente em Lisboa. ${ }^{50}$

O francês acreditava que estava lidando com instituições científicas muito inferiores às do seu país e que se relacionava com naturalistas menos qualificados. Ele considerou lastimável o estado das coleções de história natural do gabinete da Ajuda, dirigido por Vandelli. As ricas coleções provenientes, sobretudo, do Brasil e da África estavam amontoadas; os herbários de plantas exóticas, feitos por ordem da Coroa portuguesa, não tinham sido usados. Daquele material "virgem", segundo ele, não se tinha originado nenhuma planta nem ideia botânica. ${ }^{51}$ Ele afirmou que só confiscou de Ajuda as duplicatas e que identificara os exemplares que ficaram em Portugal. Assim, quando os produtos fossem identificados e classificados na França, os naturalistas portugueses poderiam saber do que se tratava: teriam uma "propriedade científica, enquanto antes possuíam apenas ervas". 52

Étienne Geoffroy Saint-Hilaire não se limitou às duplicatas, como se sabe. Até hoje, por exemplo, as exsicatas de Alexandre Rodrigues Ferreira estão no Museu de História Natural de Paris. O zoólogo também quis se apoderar dos desenhos originais da Florae Fluminensis, mas acabou por levar estampas feitas a partir dos originais: "Poder-se-ia arrancar as pranchas a um homem tão raro?" ${ }^{53}$ - escreveu ele a Georges Cuvier. Geoffroy avaliou, então, de forma extremamente positiva o que viu dos desenhos e coleções do franciscano. Porém, sua utilidade residiria no fato de que os desenhos poderiam ajudar na organização do material brasileiro, disposto de forma caótica e sem indicação de proveniência.

Portanto, as próprias imagens originais da obra de Veloso teriam valor científico quando acompanhadas das coleções. Posteriormente, depois do desmembramento do gabinete da Ajuda, da transferência dos soberanos e do próprio Veloso para o Rio, o sentido daquele manuscrito começava a se alterar. Ao que tudo indica, o fato de existirem imagens bem desenhadas juntamente com as descrições textuais fez com que a obra ganhasse valor, de forma independente de sua vinculação a um herbário ou outro tipo de

\footnotetext{
${ }^{50}$ Ver KURY, Lorelai. As coleções, a invasão francesa e o Brasil. In: VANDELLI, Domenico (ed.). $O$ gabinete de curiosidades de Domenico Vandelli. Rio de Janeiro: Dantes Editora, 2008.

51 SAINT-HILAIRE, Étienne Geoffroy. Carta aos professores do Museu de História Natural de Paris. Lisboa, 24 de maio de 1808. In: HAMY, Ernest T. La mission d'Etienne Geoffroy Saint-Hilaire en Espagne et en Portugal (1808). Histoire et documents. Paris: Masson, 1908, p. 45.

52 SAINT-HILAIRE, Étienne Geoffroy. Carta a Joseph Banks. Lisboa, s. d. Ibid., p. 51.

53 SAINT-HILAIRE, Étienne Geoffroy. Carta a George Cuvier. Lisboa, 28 de maio de 1808. Ibid., p. 48-49.
} 
coleção. Até o início do século XX, o método atual que exige na maioria das situações a vinculação das descrições a um exemplar de planta fixo (normalmente em herbário, os chamados "tipos") ainda não vigorava, o que tornava o desenho ainda mais importante. ${ }^{54}$ As normas atuais da botânica aceitam desenhos corretos como "tipos", nos casos mais antigos e quando uma referência de herbário ou similar não foi conservada, como ocorre com as descrições de Veloso. De forma independente da questão da prioridade científica, os originais da Florae Fluminense foram não raro consultados na Real Biblioteca por naturalistas locais e estrangeiros, provavelmente a fim de esclarecer dúvidas e comparar suas espécies com as de outros autores. ${ }^{55}$

O botânico francês Auguste de Saint-Hilaire foi um dos que consultaram a obra de Veloso. Em um de seus livros, ao chamar a atenção do leitor para não confundir Veloso de Miranda com Conceição Veloso, observou: ..."autor do Florae Fluminensis, do qual existem dois exemplares manuscritos na Biblioteca do Rio de Janeiro e do qual seria fortemente desejável que se publicassem os magníficos desenhos". ${ }^{56}$

Para além da botânica, nos anos que se seguiram à morte de Veloso (1811) e de seu patrono, d. Rodrigo de Souza Coutinho (1812), a memória do franciscano passou por um processo de valorização, juntamente com outros naturalistas e homens de ciência nascidos no Brasil. O que contava naquele momento não era tanto - ao que me parece - a utilidade em si da obra Florae Fluminensis, mas o reconhecimento dos trabalhos e da competência de um "brasileiro". Aquele homem tornara-se motivo de orgulho patriótico e depois nacional.

O texto anônimo Algumas reflexões sobre a história natural do Brasil e estabelecimento do Museu e Jardim Botânico em a Corte do Rio de Janeiro, ${ }^{57}$ publicado no Rio de Janeiro pela Impressão Régia em 1819, foi provavelmente o primeiro a elencar os trabalhos de Veloso como representantes da produção de "pessoas residentes no Brasil". Há indicações de que o texto tenha sido escrito por José Feliciano Fernandes Pinheiro (1774-1847), futuro visconde de São Leopoldo, que era amigo de infância dos Andradas - em Santos - e havia trabalhado como tradutor da Tipografia do Arco do Cego. Algumas reflexões... vem como

\footnotetext{
${ }^{54}$ As primeiras referências à necessidade de estabelecer tipos são de Alphonse de Candolle, em 1867.

55 Florae Fluminensis..., op. cit., p. 7.

${ }^{56}$ SAINT-HILAIRE, Auguste. Histoire des plantes les plus remarquables du Brésil et du Paraguay. Paris: Belin, 1824, p. 23.

57 [PINHEIRO, José Feliciano Fernandes]. Instrucção para os viajantes e empregados nas colonias... precedida de Algumas reflexões sobre a história natural do Brasil, e estabelecimento do Museu e Jardim Botânico em a Corte do Rio de Janeiro. Rio de Janeiro: Impressão Régia, 1819.
} 
apresentação de uma instrução para viajantes, publicada originalmente pelo Museu de História Natural de Paris em 1818. Pinheiro apresentou aí uma proposta para a organização do Museu Real que estava sendo criado no Rio de Janeiro. Além de traçar um panorama geral da história natural internacional, incluindo os autores portugueses, ele mencionava o que já fora feito por autores locais. O primeiro a ser listado foi Veloso, com a Florae Fluminensis, que o próprio autor chegara a consultar na Biblioteca Pública do Rio de Janeiro. ${ }^{58}$ São elencados também os volumes de Fazendeiro do Brasil e diversas outras obras publicadas por Veloso em Lisboa.

O nome de Fernandes Pinheiro aparece novamente relacionado ao de Veloso por ocasião das tramitações para a publicação das estampas da Florae Fluminensis, citado pelo padre Joaquim Damazo dentre os interessados pelo assunto. ${ }^{59}$ Fernandes Pinheiro viria a ser um dos sócios fundadores do Instituto Histórico do Rio de Janeiro e responsável por memórias históricas sobre o santista Alexandre de Gusmão e seu irmão, o inventor Bartolomeu de Gusmão. ${ }^{60}$ Sua obra de maior fôlego foi Anais da província de São Pedro (1822), importante esforço de síntese da história da região, na qual também se refere a Veloso. ${ }^{61} \mathrm{O}$ IHGB foi um dos responsáveis pela sedimentação da memória de "brasileiros" ilustres, dentre os quais naturalistas, médicos, inventores e demais homens de ciência. No segundo volume da Revista do IHGB, o baiano Alexandre Rodrigues Ferreira, o carioca José Pinto de Azeredo e o mineiro Mariano da Conceição Veloso foram todos transformados em brasileiros. ${ }^{62}$ Quem redigiu o elogio histórico de Veloso foi Manoel Ferreira Lagos, que seria mais tarde um dos viajantes da primeira expedição científica brasileira, responsável pela parte zoológica das pesquisas. ${ }^{63} \mathrm{O}$ tom do texto de Lagos é

\footnotetext{
${ }^{58}$ Ibid., p. XXVI.

59 Florae Fluminensis, op. cit., p. 29.

${ }^{60}$ PINHEIRO, José Feliciano Fernandes. Vida e feitos de Alexandre de Gusmão e de Bartolomeu Lourenço de Gusmão. Revista do Instituto Histórico e Geográfico Brasileiro, 65, 1841, p. 379-423.

${ }^{61}$ Ver Florae Fluminensis, op. cit., p. 7.

${ }^{62}$ LAGOS, Manuel Ferreira. Elogio histórico do padre mestre fr. José Marianno da Conceição Vellozo. Revista do Instituto Histórico e Geográfico Brasileiro, t. II, 1840, p. 610-621; MAIA, Emílio Joaquim da Silva. Elogio histórico do doutor José Pinto de Azeredo. Revista do Instituto Histórico e Geográfico Brasileiro, t. II, 1840, p. 629-635; [PONTES, Rodrigo de Souza da Silva E SÁ, Manoel Maria da Costa e]. Biographia dos brasileiros distinctos por lettras, armas, virtudes $\mathcal{E}$ c.: dr. Alexandre Rodrigues Ferreira. Revista do Instituto Histórico e Geográfico Brasileiro, t. II, 1840, p. 513-517.

${ }^{63}$ Ver SÁ, Magali Romero. A zoologia da Comissão Científica de Exploração. In: KURY, Lorelai (org.). Comissão Científica do Império. Rio de Janeiro: Andrea Jakobsson Estúdio, 2009.
} 
fundamentalmente laudatório e exalta o fato de Veloso ter aprendido história natural por seus próprios méritos, sem aprendizado formal.

A memória de Veloso ia, desse modo, sendo consolidada como a de um dos grandes naturalistas "brasileiros". Outra consagração veio por parte do botânico Francisco Freire Alemão e dos homens de ciências reunidos, entre 1850 e 1856, em torno da associação científica que acabou tomando o nome do franciscano: Sociedade Velosiana de Ciências Naturais. A escolha desse nome suscitou algum debate à época, que fez eco a críticas que a obra de Veloso sofrera em seu próprio tempo. Como apontam Fátima Nunes e João Brigola, as apreciações negativas à obra do religioso devem ser principalmente atribuídas ao botânico português Félix de Avelar Brotero - contemporâneo de Veloso - que foi contrário à publicação da Florae Fluminensis, quando da morte de seu autor. ${ }^{64}$ Do círculo de Brotero, o abade Correia da Serra, secretário da Academia das Ciências, também teria sido desfavorável à publicação da obra, pelo menos desde $1795 .{ }^{65}$ Frei Leandro do Sacramento, discípulo de Brotero que dirigiu o Jardim Botânico do Rio de Janeiro entre 1824 e 1829, não tinha igualmente em bom conceito o trabalho de naturalista de Veloso. Correia da Serra, Brotero e o próprio frei Leandro abraçavam outro referencial botânico, para o qual os moldes lineanos dos religiosos amadores pareciam absolutamente ultrapassados.

De geração posterior, Alemão foi fundador e principal fomentador da Sociedade Velosiana. Esteve envolvido nas mais importantes iniciativas em favor do fortalecimento das ciências naturais no Brasil, como a criação de instituições e periódicos especializados. Ele participou da Academia Imperial de Medicina, da Sociedade Auxiliadora da Indústria Nacional, dirigiu o Museu Nacional. Foi também professor da Faculdade de Medicina do Rio de Janeiro e da Escola Central. Em 1840, foi nomeado médico da Imperial Câmara e teve oportunidade de conviver com o estrito círculo em torno de Pedro II. Em 1859, chefiou a Comissão Científica do Império. ${ }^{66}$

Nos documentos de Freire Alemão, depositados na Biblioteca Nacional do Rio de Janeiro, encontram-se diversas anotações botânicas e históricas

\footnotetext{
${ }^{64}$ Ver LOPES, Maria Margaret. O Brasil descobre a pesquisa científica: os museus e as ciências naturais no século XIX. São Paulo: Hucitec, 1997.

${ }^{65}$ VELOSO, José Mariano da Conceição. Ofício ao (secr. de Estado...) d. Rodrigo de Souza Coutinho, op. cit.

${ }^{66}$ Sobre a Comissão, ver, entre outros: BRAGA, Renato. História da Comissão Científica de Exploração. s. l.: Imprensa Universitária do Ceará, 1962. KURY, Lorelai (org.). Comissão Científica do Império. Rio de Janeiro: Andrea Jakobsson Estúdio, 2009.
} 
sobre Veloso, relacionadas à criação da Sociedade Velosiana, mas também referentes a pesquisas com plantas igualmente estudadas pelo religioso.

Em seus manuscritos, ele informa sobre conversa que manteve, em Petrópolis, no ano de 1849, com frei Pedro de Santa Mariana e Sousa, que fora preceptor do infante Pedro e tornara-se bispo de Crisópolis. Nessa ocasião, frei Pedro teria dito que convivera com Veloso no Convento de Santo Antônio e que julgava muito estranho ele ter produzido a Florae Fluminensis, pois era incapaz de classificar qualquer planta. Alemão observou que "provavelmente este conceito que faz o Bispo de Veloso lhe foi sugerido por Frei Leandro [do Sacramento], de quem ele fez grande elogio". ${ }^{67}$

O botânico inquiriu outros personagens a respeito de Veloso e também de Veloso de Miranda, buscando estabelecer claramente as biografias dos dois, provavelmente para evitar confusões.

Em carta a Antônio Moniz de Souza, ${ }^{68}$ que estudara com Veloso, Alemão lhe pedira:

(...) dar-me uma notícia de tudo aquilo de tudo que [lhe] lembrar a respeito do Pe. Veloso: em que se ocupava ele no convento? Quais eram suas conversas e projetos? Seu modo de viver, e os amigos que o frequentavam: e tudo quanto se observou sobre sua saúde, seu modo de viver e enfim, se sabe alguma coisa de sua morte. ${ }^{69}$

Essas anotações são posteriores ao início da Sociedade Velosiana. Talvez Freire Alemão intencionasse escrever alguma biografia de Veloso. De todo modo, é certo que buscou o máximo de informações que pôde.

Junto às anotações de caráter biográfico, Freire Alemão pesquisava a obra de descrição botânica do franciscano. Por exemplo, ele estabeleceu uma lista intitulada "Lugares nomeados por Velloso ou sítios das plantas", buscando as equivalências das denominações latinas de Veloso para designações que se pudesse reconhecer mais facilmente. ${ }^{70}$ Assim, "ad radices Alpium

\footnotetext{
${ }^{67}$ ALEMÃO, Francisco Freire. Notícias a respeito dos naturalistas Joaquim Veloso de Miranda e José Mariano da Conceição Veloso, colhidas de vários informantes, 1849. Biblioteca Nacional do Rio de Janeiro, ms. I - 28, 09, 54.

${ }^{68}$ Sobre esse personagem, ver: SANTOS, Laura Carvalho dos. Antônio Moniz de Souza, o "Homem da natureza": ciências e plantas medicinais no início do século XIX. História, Ciências, Saúde - Manguinhos, v. 15, n. 4, 2008, p. 1025-1038.

${ }^{69}$ ALEMÃO, Francisco Freire. Carta a Moniz S., 1854. Biblioteca Nacional do Rio deJaneiro, ms. I-28,01, 50.

${ }^{70}$ Este tipo de procedimento consta do trabalho clássico de STELLFELD, Carlos. Os dois Vellozo. Rio de Janeiro: Gráfica Editora Souza, 1952, e continua sendo feito por botânicos atuais, como é o caso de LIMA, Haroldo C., op. cit.
} 
Fluminensium $=$ Serra do Mar" ou "Silvis maritimis regii praedii Sanctae Crucis = Santa Cruz". Em certos casos, Freire Alemão teve dúvidas: "campis apricis transalpinis $=(\text { Sima da Serra? })^{\prime \prime} .^{71}$

Freire Alemão efetivamente usava a Florae Fluminensis de Veloso como material de estudo botânico para suas próprias pesquisas, descrições e classificações. Como exemplo, em 1845, renomeou o Pau Pereira, já descrito por Veloso (Tabernaemontana laevis), como Geissorpermum vellosii, criando um novo gênero. ${ }^{72}$ A proximidade entre seus trabalhos foi provavelmente reforçada pelo fato de terem coletado muitas vezes nas mesmas regiões. O médico do imperador nascera na Serra do Mendanha, para onde se retirou quando diminuíram suas atribuições na capital. Sem dúvida, Alemão dedicou vários anos a estudar a flora do Ceará, porém, a maior parte de sua vida foi ocupada com pesquisas sobre as plantas dos arredores do Rio de Janeiro. É bastante interessante compreender a admiração que deve ter sentido por Veloso, homem de outra geração, vindo de um universo sem especialização científica. A prática da botânica atual e a da época de Freire Alemão pressupõe a ida às fontes e a reapropriação dos naturalistas do passado. No seu caso, o pertencimento a um ambiente intelectual para o qual o sentimento nacional era um componente essencial provavelmente favoreceu a abordagem historicizada da botânica. Como já foi frisado acima, ele participou ativamente da construção do que seria uma ciência nacional brasileira.

Este tipo envolvimento fez com que Freire Alemão se imbricasse, desde 1848, na continuação da publicação da parte inédita da Florae Fluminensis, como atesta a correspondência oficial de frei Camilo de Monserrate. O botânico avaliou o que e como deveria ser publicado, a partir do cotejamento dos manuscritos com o que já havia sido impresso. ${ }^{73}$

\section{$* * *$}

A Florae Fluminensis é atualmente fruto de uma relativamente longa construção, que a conduziu do Iluminismo colonial ao mundo da botânica especializada. Porém, a sua publicação e a afirmação de Veloso como um "grande brasileiro" se deram no âmbito das instituições imperiais, empenha-

\footnotetext{
${ }^{71}$ ALEMÃO, Francisco Freire. Lugares nomeados por Velloso ou sítios das plantas. s.d. Biblioteca Nacional do Rio de Janeiro, ms. I - 28, 10, 05.

${ }^{72}$ Ver ALMEIDA, Márcia R. et al. Pereirina: o primeiro alcaloide isolado no Brasil? Revista Brasileira de Farmacognosia. v. 19, n. 4, 2009, p. 942-952.

${ }^{75}$ Ver Flora Fluminense, op. cit., p. 144-148.
} 
das na afirmação da nacionalidade. Inicialmente associada às artes e ciências úteis, a grande obra botânica virou um testemunho do gênio nacional. A botânica permitiu a incorporação de uma obra que se valia do sistema de Lineu, impressa no século XIX. Assim, história, memória, identidade nacional e ciências se unem para compreender esses documentos, que circularam entre Rio de Janeiro, Lisboa e Paris. Em torno da publicação da parte inédita dos manuscritos, frei Camilo de Monserrate, em 1863, comparou o franciscano aos mais reconhecidos nomes da história natural, baseado em uma abordagem historicizada da botânica e em um desejo de encontrar no passado um brasileiro que figurasse no universo seleto dos cientistas:

Direi, prosseguindo, que, seja defeituosa como for, em relação ao estado atual da Ciência, a Flora Fluminensis de Veloso continua a ser obra capital, por ser especial a uma província botânica, por serem suas descrições não somente exatas, minuciosas e elegantes, como ainda de idônea aplicação hoje de plantas a que se referem: Constando talvez seu atraso sobretudo na sinonímia e na classificação. Apesar deste atraso, os botânicos mais eminentes dos nossos tempos, entre os quais o Sr. Dr. Martius, nunca deixam ainda hoje de citar a Flora de Veloso, quando tratam de alguma planta descrita por estes; pelo mesmo modo que, apesar dos progressos da Ciência, guardam ainda sua preeminência as Floras, especiais a certas regiões botânicas, de autores contemporâneos de Veloso ou anteriores ao tempo dele, tais como Aublet, Ruiz e Pavón, Plumier, Jacquin, Banks, (...) cujas obras são procuradas com empenho, consultadas com respeito. ${ }^{74}$

Portanto, a memória de Veloso não foi construída exclusivamente pelos métodos da história ou pelas instituições que conservavam seu espólio. A botânica é uma disciplina que interage com os documentos do passado, trazendo-os instrumentalmente para seu campo referencial. Foi em confluência entre uso técnico e uso simbólico que Florae Fluminensis transformou-se em obra e Veloso em cientista nacional. Cabe aos historiadores situar no tempo e no espaço os documentos que deixou e as camadas de representação que constituem sua figura.

\section{Referências bibliográficas}

ABREU, Jeronimo Vieira de. Brevíssima instrucção para uso dos fabricantes de anil nas colonias de sua majestade fidelíssima, 1785. Biblioteca Nacional do Rio de Janeiro, ms., 05, 01, 05.

\footnotetext{
${ }^{74}$ MONSERRATE, frei Camilo de. Ofício ao marquês de Olinda, respondendo aos quesitos formulados acerca da atual condição e projeto da impressão da Flora Fluminense, 20 de julho de 1863. In: Flora Fluminensis, op. cit., p. 146.
} 
ALEMÃO, Francisco Freire. Lugares nomeados por Velloso ou sítios das plantas. s.d. Biblioteca Nacional do Rio de Janeiro, ms. I - 28, 10, 05. $28,01,50$.

Carta a Moniz S. 1854. Biblioteca Nacional do Rio de Janeiro, ms. I -

Notícias a respeito dos naturalistas Joaquim Veloso de Miranda e José Mariano da Conceição Veloso, colhidas de vários informantes, 1849. Biblioteca Nacional do Rio de Janeiro, ms. I - 28, 09, 54.

ALMEIDA, Márcia R. et al. Pereirina: o primeiro alcaloide isolado no Brasil? Revista Brasileira de Farmacognosia, v. 19, n. 4, 2009, p. 942-952.

BARRETO, Domingos Alves Branco Muniz. Regras pelas quais se devem estampar as ervas medicinais e fazer recolher as suas ramas e raízes em tempos próprios, não só do modo que apontam os melhores autores, mas segundo as reflexões que tenho feito a este respeito. Manuscrito. Biblioteca da Academia das Ciências de Lisboa, transcrito em O feliz clima do Brasil. Rio de Janeiro: Dantes, 2008.

. Relação que contém por lembrança a descrição de uma diminuta parte da comarca dos Ilhéus desta capitania da Bahia, por onde viajei, e do que nela observei. Manuscrito. Biblioteca da Academia das Ciências de Lisboa, transcrito em $O$ feliz clima do Brasil. Rio de Janeiro: Dantes, 2008.

BIAGIOLI, Mario. From print to patents: living on instruments in early modern Europe. History of Science, XLIV, 2006, p. 139-186.

BRAGA, Renato. História da Comissão Científica de Exploração. s. l.: Imprensa Universitária do Ceará, 1962.

BRET, Patrice. "Ils ne forment tous q'une même république": Académiciens, amateurs et savants étrangers dans la correspondance des chimistes à la fin du 18e. siècle. Dix-Huitième Siècle, 40, 2008, p. 263-279.

CALAFATE, Pedro. A ideia de natureza no século XVIII em Portugal. Lisboa: Imprensa Nacional/Casa da Moeda, 1994.

CÂMARA, Manuel Arruda da. Carta a frei José da Conceição Veloso. Recife, 2 de junho de 1799. Museu Paulista, ms. I.1 I-2-2-275.

CAMPOS, Fernanda de et al. (org.). A casa literária do Arco do Cego (1799-1801) - Bicentenário: "sem livros não há instrução". Lisboa: Biblioteca Nacional/ Imprensa Nacional/Casa da Moeda, 1999.

CASTRO, Martinho de Melo e. Ofício a Luis de Vasconcelos e Souza. Lisboa, 6 de março de 1786. In: Livros de registro das cartas régias e de ofício remetidas da Corte e do secretário de Estado da repartição da Marinha e Domínios Ultramarinos dirigidas a Luís de Vasconcelos e Souza, vice-rei do Brasil. Biblioteca Nacional do Rio de Janeiro, ms. 04, 04, 008.

FARIA, Miguel. A imagem útil. Lisboa: Universidade Autônoma de Lisboa, 2002.

FLECK, Eliane. Sobre licores e xaropes: práticas curativas e experimentalismos jesuíticos nas reduções da Província Jesuítica do Paraguai (séculos XVII-XVIII). In: KURY, Lorelai $\mathcal{E}$ GESTEIRA, Heloisa (org.). Ensaios de história das ciências no Brasil: das Luzes à nação independente. Rio de Janeiro: EdUerj, 2012.

Flora Fluminensis: Documentos. Rio de Janeiro: Arquivo Nacional, 1961. 
FUSÉE-AUBLET, Jean-Baptiste. Histoire des plantes de la Guiane françoise rangées suivant la méthode sexuelle. Paris: Didot jeune, 1775.

GAMA, José de Saldanha da. Biographia e apreciação dos trabalhos do botanico brasileiro frei José Marianno Conceição Velloso. Rio de Janeiro: Typ. de Pinheiro E C., 1869.

GESTEIRA, Heloísa. As virtudes das plantas: circulação de ideias e práticas médicas na América, séculos XVI-XVIII. In: ALMEIDA, Marta de \& VERGARA, Moema (org.). Ciência, história e historiografia. Rio de Janeiro: Via Lettera, 2008.

JACQUIN, Nikolaus Joseph. Selectarum stirpium Americanarum historia. Viena: Of. Krausiana, 1763.

KURY, Lorelai. A ciência útil em O patriota (Rio de Janeiro, 1813-1814). Revista Brasileira de História das Ciências, v. 4, 2011. Estúdio, 2009.

(org.). Comissão Científica do Império. Rio de Janeiro: Andrea Jakobsson

As coleções, a invasão francesa e o Brasil. In: VANDELLI, Domenico (ed.). O gabinete de curiosidades de Domenico Vandelli. Rio de Janeiro: Dantes Editora, 2008. Histoire naturelle et voyages scientifiques (1780-1830). Paris: L'Harmattan, 2001. . Manuel Arruda da Câmara: a República das Letras nos sertões. In: Idem (org.). Sertões adentro: viagens nas caatingas, séculos XVI a XIX. Rio de Janeiro: Andrea Jakobsson Estúdio, 2012.

LEME, Antonio Pires da Silva Pontes. Carta a d. Rodrigo de Sousa Coutinho. Bahia, 5 de abril, de 1798. Manuscrito. Biblioteca Nacional do Rio de Janeiro. Transcrito em SILVA, Andrée Mansuy-Diniz. Portrait d'un homme d'État: d. Rodrigo de Souza Coutinho, Comte de Linhares, 1755-1812, vol. II: L'homme d'État, 1796-1812. Paris: Centre Culturel Calouste Gulbenkian, 2006.

LIMA, Haroldo C. de. Leguminosas da Flora Fluminensis - J. M. da C. Vellozo - lista atualizada das espécies arbóreas. Acta Botanica Brasilica, v. 9, n. 1, julho de 1995, p. 123-146.

LINNAEUS, Carolus. Systema naturce, sive regna tria naturce systematice proposita per classes, ordines, genera, \& species. Leiden: Haak, 1735.

\section{Genera plantarum. Leiden: C. Wishoff, 1737.}

Philosophia botanica. Estocolmo: G. Kisseweter, 1751.

LINNÉ, Carl. L'équilibre de la nature. Textos anotados por Camille Limoges. Paris: J. Vrin, 1972.

LAGOS, Manuel Ferreira. Elogio histórico do padre mestre fr. José Marianno da Conceição Vellozo. Revista do Instituto Histórico e Geográfico Brasileiro, t. II, 1840, p. 610-621.

LOPES, Maria Margaret. O Brasil descobre a pesquisa científica: os museus e as ciências naturais no século XIX. São Paulo: Hucitec, 1997.

MAIA, Emílio Joaquim da Silva. Elogio histórico do doutor José Pinto de Azeredo. Revista do Instituto Histórico e Geográfico Brasileiro, t. II, 1840, p. 629-635.

MARQUESE, Rafael de Bivar. Feitores do corpo, missionários da mente. Senhores, letrados e o controle dos escravos nas Américas, 1660-1860. São Paulo: Companhia das Letras, 2004.

McCLELLAN III, James E. \& REGOURD, François. The colonial machine: French science and overseas expansion in the old regime. Turnhout: Brepols Publishers, 2011.

MONSERRATE, frei Camilo de. Ofício ao marquês de Olinda, respondendo aos 
quesitos formulados acerca da atual condição e projeto da impressão da Flora Fluminense. 20 de julho de 1863. In: Flora Fluminensis: Documentos. Rio de Janeiro: Arquivo Nacional, 1961.

NICKELSEN, Kärin. Draughtsmen, botanists and nature: the construction of eighteenth-century botanical Illustration. Dordrecht: Springer, 2006.

NUNES, Maria de Fátima \& BRIGOLA, João Carlos. José Mariano da Conceição Veloso (1742-1811) - um frade no universo da natureza. In: CAMPOS, Fernanda de et al. (org.). Casa Literária do Arco do Cego (1799-1801). Bicentenário: "sem livros não há instrução". Lisboa: Biblioteca Nacional/ Imprensa Nacional/Casa da Moeda, 1999.

NUNES, Maria de Fátima. Imprensa periódica científica (1772-1852). Lisboa: Estar, 2001.

PATACA, Ermelinda Moutinho. Terra, água e ar nas viagens científicas portuguesas (17551808). Tese de doutorado, Campinas, Instituto de Geociências, 2006.

PESAVENTO, Fábio. Novas perspectivas sobre o comércio de anil no Rio de Janeiro colonial: 1749-1820. Revista de História Econômica e de Economia Regional Aplicada, v. 1, n. 1, jan-jul de 2006, p. 1-19.

PEREIRA, Magnus R. de Mello. D. Rodrigo e frei Mariano: a política portuguesa de produçãodesalitrena virada do séculoXVIII para oXIX. Topoi, vol. 15,n.29,2014, p.498-526.

[PINHEIRO, José Feliciano Fernandes]. Instrucção para os viajantes e empregados nas colonias... precedida de Algumas reflexões sobre a história natural do Brasil, e estabelecimento do Museu e Jardim Botânico em a Corte do Rio de Janeiro. Rio de Janeiro: Impressão Régia, 1819.

PINHEIRO, José Feliciano Fernandes. Vida e feitos de Alexandre de Gusmão e de Bartolomeu Lourenço de Gusmão. Revista do Instituto Histórico e Geográfico Brasileiro, 65, 1841, p. 379-423.

[PONTES, Rodrigo de Souza da Silva E SÁ, Manoel Maria da Costa e]. Biographia dos brasileiros distinctos por lettras, armas, virtudes $\&$ c.: dr. Alexandre Rodrigues Ferreira. Revista do Instituto Histórico e Geográfico Brasileiro, t. II, 1840, p. 513-517.

PLUMIER, Charles. Description des plantes de l'Amérique avec leurs figures. Paris: Imprimerie Royale, 1693.

[RANGEL, José Correa]. Mappa botanico para uzo do ilmo. e exmo. sr. Luis de Vasconcellos e Soiza, s.l., s. d. Biblioteca Nacional do Rio de Janeiro, ms. 49, 03, 07, n. 4.

REIS, Fernando Egídio. Felicidade, utilidade e instrução. A divulgação científica no Jornal Enciclopédico dedicado à Rainha; 1779; 1788-1793; 1806. Porto: Porto Editora, 2005.

Resumo do systema sexual botanico. Biblioteca Nacional do Rio de Janeiro, ms. I - 13, 02, 13.

RÖWER, frei Basílio. O Convento de Santo Antônio do Rio de Janeiro. Sua história, memórias, tradições. Rio de Janeiro: Jorge Zahar, 2008.

SÁ, Magali Romero. A zoologia da Comissão Científica de Exploração. In: KURY, Lorelai (org.). Comissão Científica do Império. Rio de Janeiro: Andrea Jakobsson Estúdio, 2009.

SAINT-HILAIRE, Auguste de. Histoire des plantes les plus remarquables du Brésil et du Paraguay. Paris: Belin, 1824.

SAINT-HILAIRE, Étienne Geoffroy. Carta a Joseph Banks, Lisboa, s. d.. In: HAMY, Ernest Théodore. La mission d'Etienne Geoffroy Saint-Hilaire en Espagne et en Portugal (1808). Histoire et documents. Paris: Masson, 1908. 
Carta aos professores do Museu de História Natural de Paris. Lisboa, 24 de maio de 1808. In: HAMY, Ernest Théodore. La mission d'Etienne Geoffroy Saint-Hilaire en Espagne et en Portugal (1808). Histoire et documents. Paris: Masson, 1908.

Carta a George Cuvier. Lisboa, 28 de maio de 1808. In: HAMY, Ernest Théodore. La mission d'Etienne Geoffroy Saint-Hilaire en Espagne et en Portugal (1808). Histoire et documents. Paris: Masson, 1908.

SANTOS, Laura Carvalho dos. Antônio Moniz de Souza, o "Homem da natureza": ciências e plantas medicinais no início do século XIX. História, Ciências, Saúde Manguinhos, v. 15, n. 4, 2008, p. 1025-1038.

SCOTT-PARISH, Susan. American curiosity. Cultures of natural history in the colonial British Atlantic World. Williamsburg: Omohundro Institute of Early American History and Culture, 2006.

SHAPIN, Steven. Never pure. Historical studies of science as if it was produced by people with bodies, situated in time, space, culture and society, and struggling for credibility and authority. Baltimore: The Johns Hopkins University Press, 2010.

SOUZA, Luís de Vasconcelos e. Carta a Martinho de Melo e Castro. Rio de Janeiro, 17 de junho de 1783. In: Livros de registro das cartas régias e de ofício remetidas da Corte e do secretário de Estado da repartição da Marinha e Domínios Ultramarinos dirigidas a Luís de Vasconcelos e Souza, vice-rei do Brasil. Biblioteca Nacional do Rio de Janeiro, ms. 04, 04, 005.

STELLFELD, Carlos. Os dois Vellozo. Rio de Janeiro: Gráfica Editora Souza, 1952.

VANDELLI, Domingos. Dicionário dos termos técnicos de história natural. Coimbra: Real Oficina da Universidade, 1788.

VELOSO, Mariano da Conceição. Florae Fluminensis seu discriptionum plantaru praefectura fluminensi sponte nascentium liber primus ad systema sexuale, 2 v., [1790]. Biblioteca Nacional do Rio de Janeiro, ms. 02, 04, 005-006.

VELOSO, Mariano da Conceição. Florae Fluminensis: Icones fundamentales, 11 v., [1790]. Biblioteca Nacional do Rio de Janeiro, ms. I - 17, 01, 001 - I - 17, 06, 001.

VELOSO, Mariano da Conceição. Florae Fluminensis Icones. Paris: Senefelder, 11 vol., 1827.

VELOSO, José Mariano da Conceição. Ofício ao (secr. de Estado...) d. Rodrigo de Souza Coutinho.Lisboa, 1795. Arquivo Histórico Ultramarino, ms.: AHU, Reino, cx.30, pasta 7.

VELlOSO, José Mariano da Conceição. Fazendeiro do Brasil. Tomo II, parte I, Tinturaria. Lisboa: Impressão Régia, 1806.

VELLOZO, Mariano da Conceição. Florae Fluminensis seu descriptionum plantarum praefectura fluminensi sponte nascentium: liber primus ad systema sexuale concinnatus... Rio de Janeiro: Machado $\mathcal{E}$ C., 1881.

VILLALTA, Luiz Carlos. Impressão em Portugal: da política régia às publicações ilegais (c. 1750-1806). In: VERRI, Gilda. M. Whitaker. (org.). Memorat: Memória e cultura escrita na formação brasileira. Recife: Universidade Federal de Pernambuco, 2011. 


\section{Imagem A}

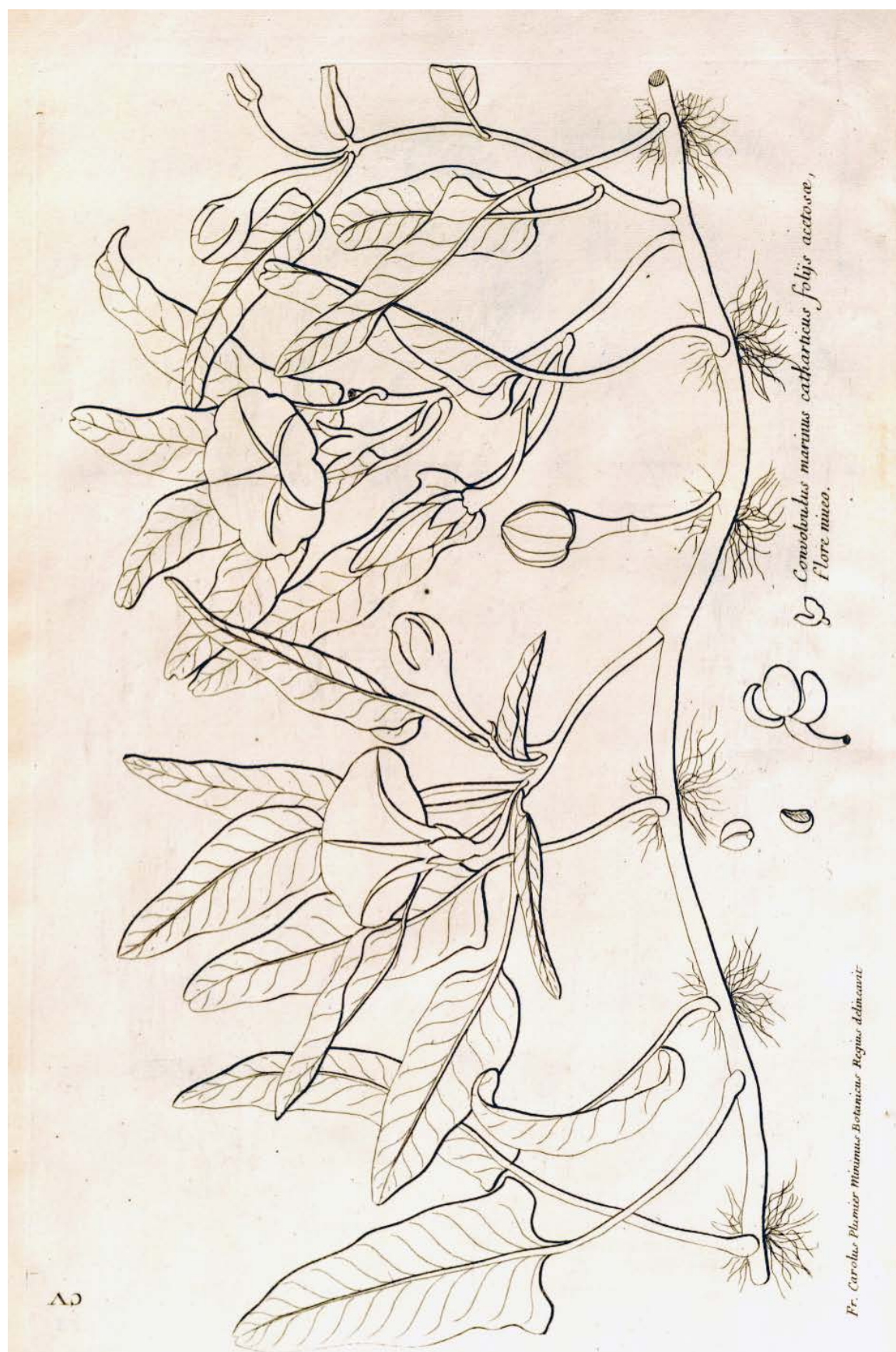

PLUMIER, Charles. Description des plantes de l'Amérique avec leurs figures. Paris: Imprimerie Royale, 1693, Prancha CV, gravura. 


\section{Imagem B}

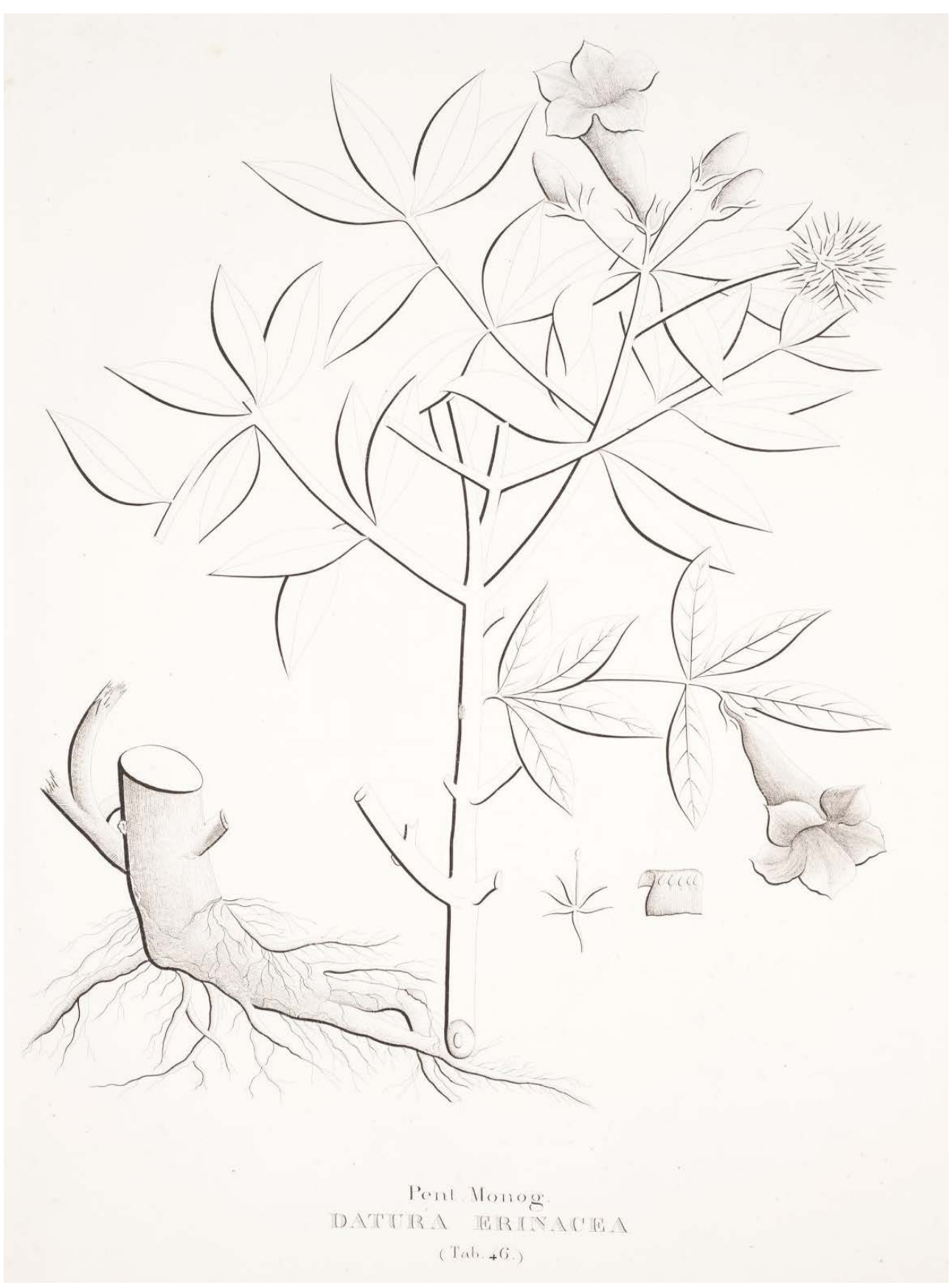

VELOSO, Mariano da Conceição. Florae Fluminensis Icones. Paris: Senefelder, 1827, vol. II, Prancha 46. 
rev. hist. (São Paulo), n. 172, p. 243-277, jan.-jun., 2015 http://dx.doi.org/10.11606/issn.2316-9141.rh.2015.98752
Lorelai B. Kury

Onaturalista Veloso

\section{Imagem C}
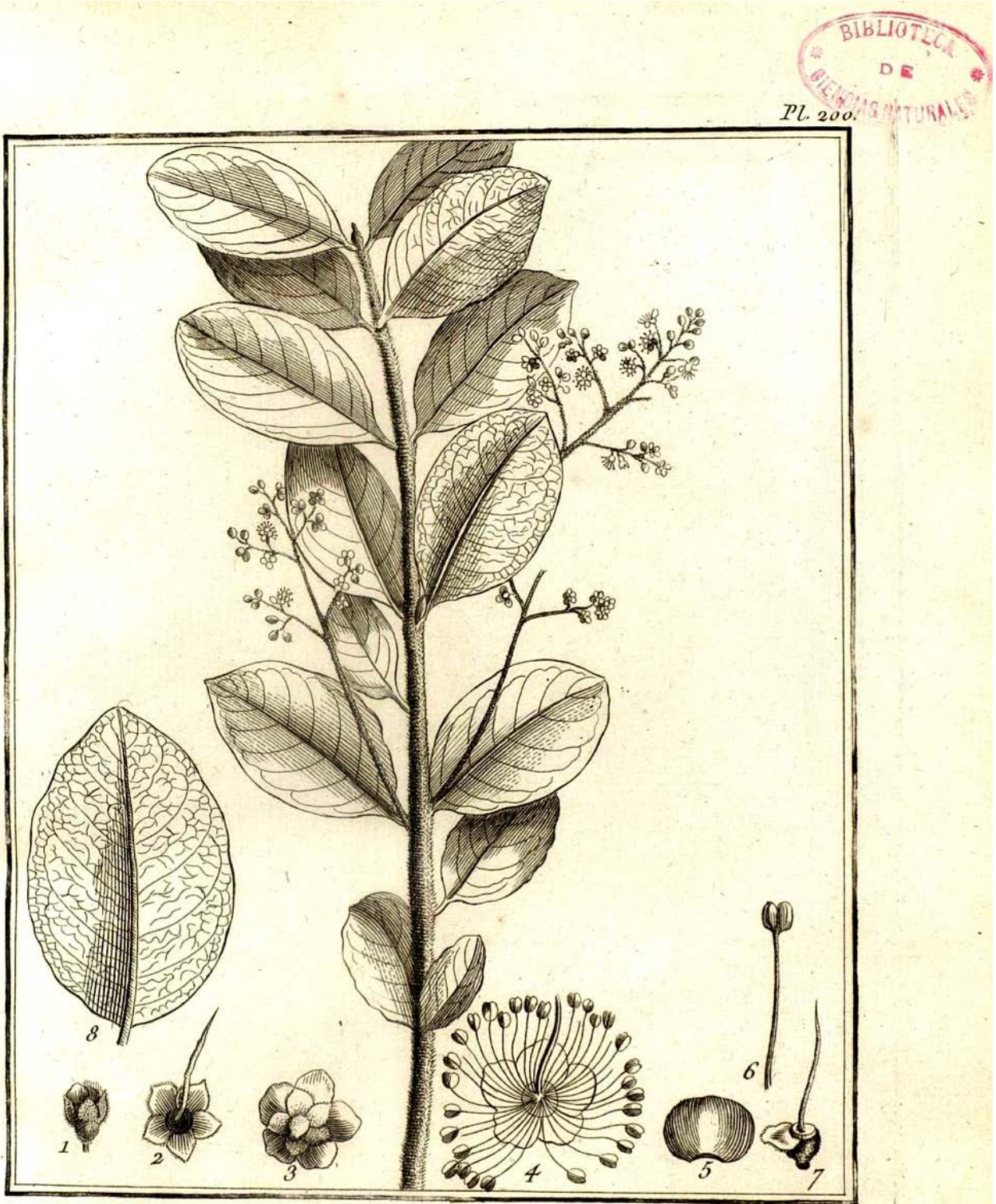

Eugenía Tomentoso.

FUSÉE-AUBLET, Jean-Baptiste. Histoire des plantes de la Guiane françoise rangées suivant la méthode sexuelle. Paris: Didot jeune, 1775, t. 4. 


\section{Imagem D}

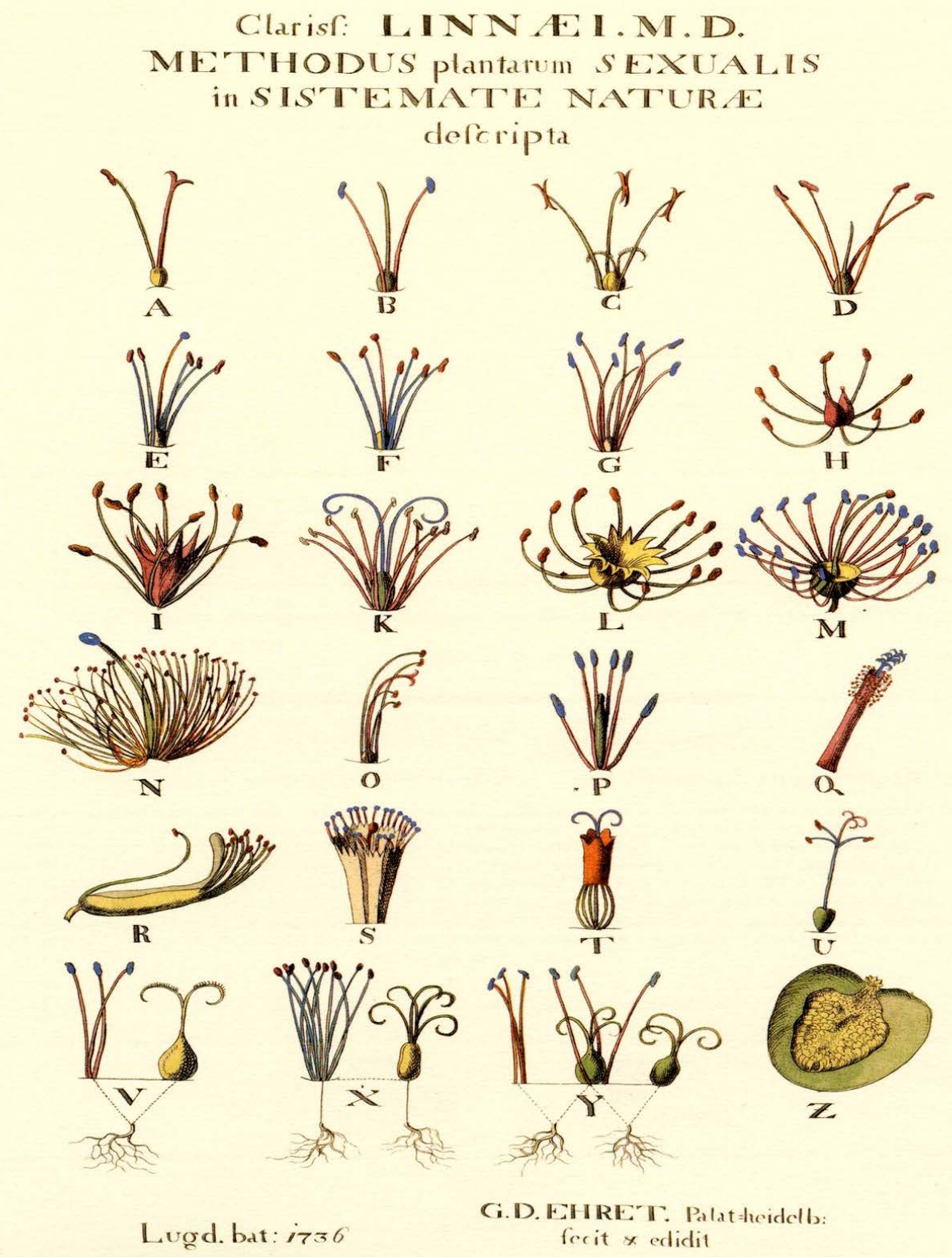

EHRET, Georg. Methodus Plantarum Sexualis in sistemate naturae descripta. Leiden, 1736, desenho aquarelado. 
rev. hist. (São Paulo), n. 172, p. 243-277, jan.-jun., 2015 http://dx.doi.org/10.11606/issn.2316-9141.rh.2015.98752
Lorelai B. Kury

0 naturalista Veloso

\section{Imagem E}

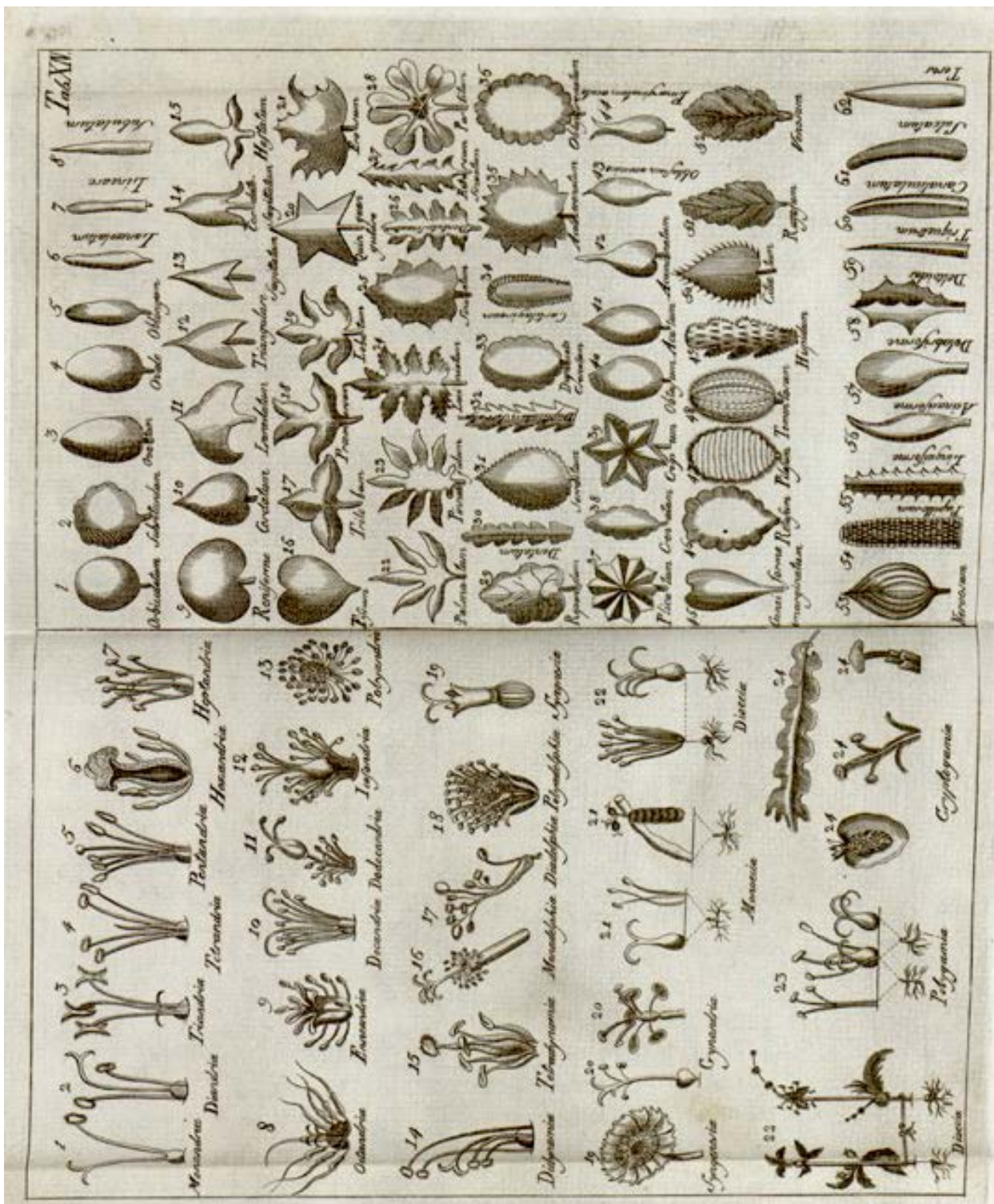

VANDELLI, Domingos. Dicionário do termos técnicos de história natural. Coimbra: Real Oficina da Universidade, 1788, prancha XIV. 
rev. hist. (São Paulo), n. 172, p. 243-277, jan.jun., 2015 http://dx.doi.org/10.11606/issn.2316-9141.rh.2015.98752
Lorelai B. Kury

0 naturalista Veloso

\section{Imagem F}

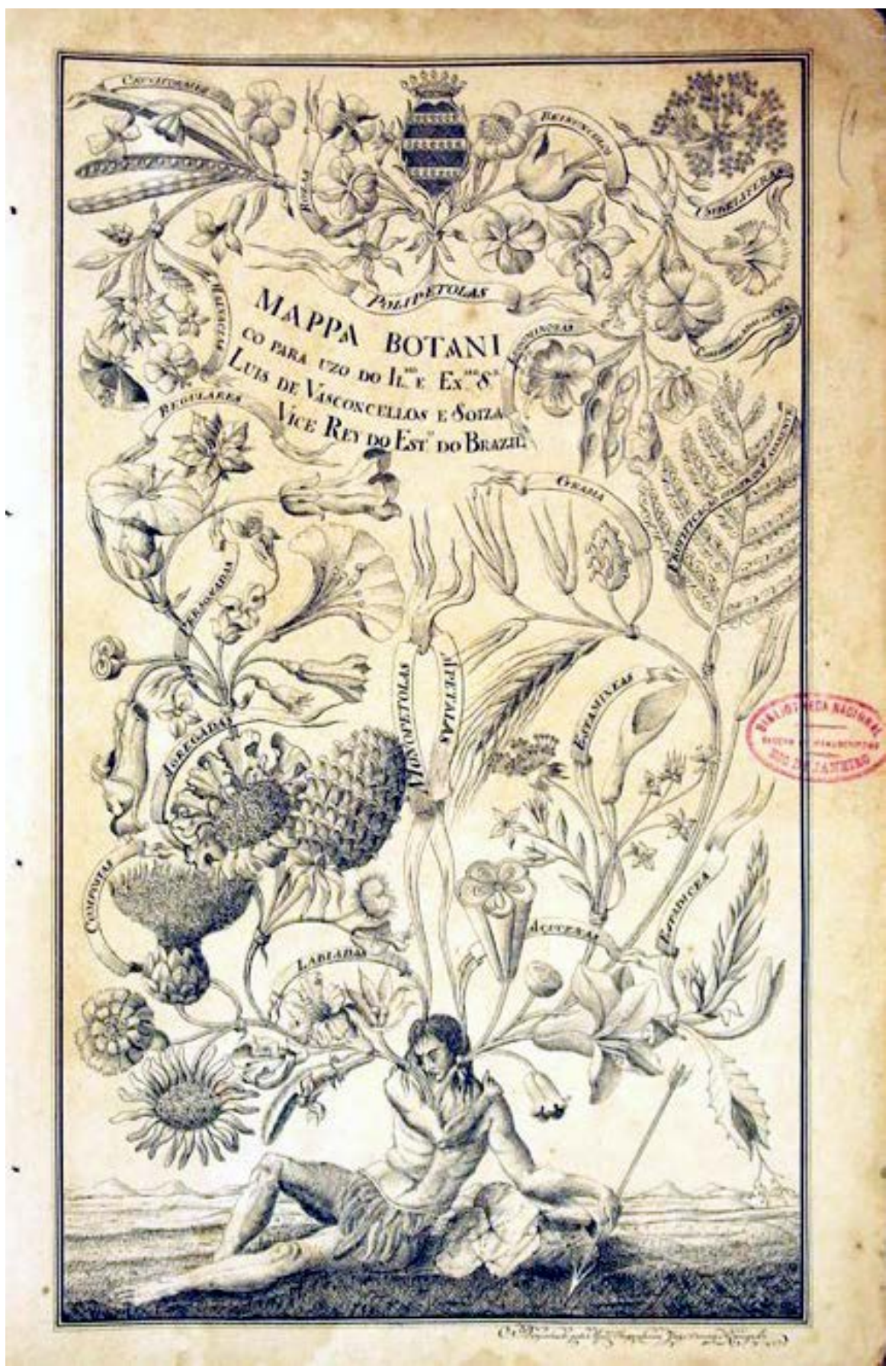

RANGEL, José Correa. Mappa botanico para uzo do Ilmo. e Exmo. Sr. Luis de Vasconcellos e Soiza, s.l., s.d.. Manuscrito, Biblioteca Nacional do Rio de Janeiro. 
rev. hist. (São Paulo), n. 172, p. 243-277, jan.jun., 2015 http://dx.doi.org/10.11606/issn.2316-9141.rh.2015.98752
Lorelai B. Kury

0 naturalista Veloso

\section{Imagem G}

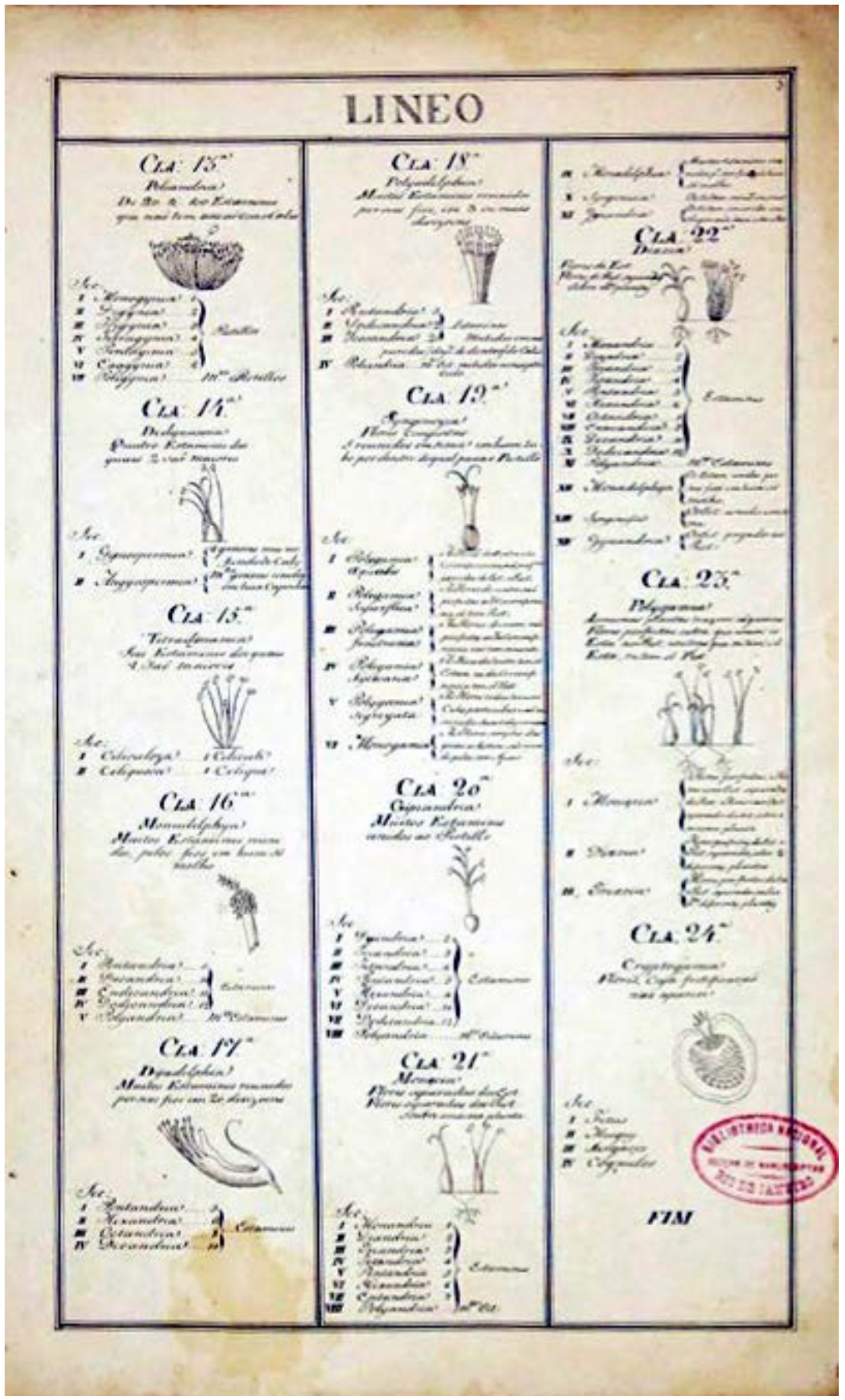

RANGEL, José Correa. Mappa botanico para uzo do Ilmo. e Exmo. Sr. Luis de Vasconcellos e Soiza, s.l., s.d.. Manuscrito, Biblioteca Nacional do Rio de Janeiro. 